\title{
Depletion of nucleus accumbens dopamine leads to impaired reward and aversion processing in mice: relevance to motivation pathologies
}

Running Title: Nucleus accumbens dopamine and motivation in mice

Giorgio Bergamini ${ }^{1,5}$, Hannes Sigrist ${ }^{1}$, Boris Ferger $^{2}$, Nicolas Singewald ${ }^{3}$, Erich Seifritz $^{4,5}$, Christopher R. Pryce ${ }^{1,5}$

1 Preclinical Laboratory for Translational Research into Affective Disorders, Department of Psychiatry, Psychotherapy and Psychosomatics, Psychiatric Hospital, University of Zurich, Switzerland

2 CNS Diseases Research Germany, Boehringer Ingelheim Pharma GmbH \& Co. KG., Biberach, Germany

3 Department of Pharmacology and Toxicology, Institute for Pharmacy and CMBI, University of Innsbruck, Austria

4 Department of Psychiatry, Psychotherapy and Psychosomatics, Psychiatric Hospital, University of Zurich, Switzerland

5 Neuroscience Center Zurich, University of Zurich and ETH Zurich, Switzerland

Corresponding author: Prof. Christopher Pryce, PLaTRAD, Department of Psychiatry, Psychotherapy \& Psychosomatics, Psychiatric Hospital, University of Zurich, August ForelStrasse 7, CH-8008 Zürich, Switzerland; Tel: +41 (0)44 634 8921; christopher.pryce@bli.uzh.ch 


\section{ABSTRACT}

Dopamine (DA) neurotransmission, particularly the ventral tegmental area-nucleus accumbens (VTA-NAcc) projection, underlies reward and aversion processing, and deficient DA function could underlie motivational impairments in psychiatric disorders. 6hydroxydopamine (6-OHDA) injection is an established method for chronic DA depletion, principally applied in rat to study NAcc DA regulation of reward motivation. Given the increasing focus on studying environmental and genetic regulation of DA function in mouse models, it is important to establish the effects of 6-OHDA DA depletion in mice, in terms of reward and aversion processing. This mouse study investigated effects of 6-OHDA-induced NAcc DA depletion using the operant behavioural test battery of progressive ratio schedule (PRS), learned non-reward (LNR), learned helplessness (LH), treadmill, and in addition Pavlovian fear conditioning. 6-OHDA NAcc DA depletion, confirmed by ex vivo HPLC-ED, reduced operant responding: for gustatory reward under effortful conditions in the PRS test; to a stimulus recently associated with gustatory non-reward in the LNR test; to escape footshock recently experienced as uncontrollable in the LH test; and to avoid footshock by physical effort in the treadmill test. Evidence for specificity of effects to NAcc DA was provided by lack of effect of medial prefrontal cortex DA depletion in the LNR and LH tests. These findings add significantly to the evidence that NAcc DA is a major regulator of behavioural responding, particularly at the motivational level, to both reward and aversion. They demonstrate the suitability of mouse models for translational study of causation and reversal of pathophysiological DA function underlying motivation psychopathologies.

Key words: mouse; dopamine; nucleus accumbens; prefrontal cortex; reward; aversion; motivation;

depression 


\section{INTRODUCTION}

Dopamine (DA) neurons with cell bodies in the ventral tegmental area (VTA) innervate several brain regions, and primary among these are the nucleus accumbens (NAcc), prefrontal cortex (PFC), amygdala and hippocampus (Lammel et al., 2008; Sesack and Grace, 2010). The NAcc is part of the ventral striatum and has extensive connectivity with other brain regions: in addition to the VTA input, it receives excitatory afferents from PFC and amygdala and inhibitory afferents from ventral pallidum (VP). Major projection regions of the NAcc include, reciprocally, VP and VTA (Sesack and Grace, 2010). Nucleus accumbens DA signalling modulates behavioural responsiveness to stimuli in terms of stimulus-stimulus learning, response-stimulus (operant) learning, and the motivation underlying behaviour directed at positive and negative stimuli (Salamone and Correa, 2012; Wise, 2004). Altered processing of positive- and negative-valence stimuli is characteristic of various psychiatric disorders, including depression and schizophrenia (Eshel and Roiser, 2010; Wang et al., 2015). For example, low motivation for reward underlies the core loss-of-interest symptom in depression and the core negative symptoms in schizophrenia; low motivation to cope with aversive stimuli likely contributes to both the perceived loss of control underlying helplessness (Nunes et al., 2013; Pryce et al., 2011; Treadway and Zald, 2011) and to fatigue (Demyttenaere et al., 2005). In the research domain criteria (RDoC) framework for mental health research (Cuthbert and Insel, 2013), motivation for reward is a dimension in the domain Positive valence systems, and emotions to and motivations induced by aversive stimuli are dimensions in the domain Negative valence systems (Cuthbert and Insel, 2013). Integrating the evidence for the importance of DA in regulating motivation with that for motivation pathologies, reduced DA function has been hypothesized as a major pathophysiological factor in depression (Dunlop and Nemeroff, 2007) and negative symptomatology in schizophrenia (Whitton et al., 2015). For example, using functional magnetic resonance imaging, reduced activity in the ventral striatum when anticipating reward was observed in both depression and schizophrenia patients compared to healthy controls (Arrondo et al., 2015; Hagele et al., 2015).

Animal studies are essential to increase understanding of contributions of DA to adaptive and disrupted processing of rewarding and aversive stimuli. Much of the evidence for the importance of NAcc DA function in the modulation of goal-directed behaviour has been obtained in loss-of-function experiments conducted in rats. Infusion of the monoamine neurotoxin 6-hydroxydopamine (6-OHDA) into the NAcc, leading to specific degeneration of DA fibre terminals (Stott and Barker, 2014), is the most established method (Aberman and Salamone, 1999). It has been primarily applied to study NAcc DA in the processing of gustatory reward stimuli. In rat, in a free-choice paradigm, NAcc DA depletion delays 
development of preference for sucrose solution relative to water (Martinez-Hernandez et al., 2012). NAcc DA depletion impairs both the operant acquisition of response-outcome learning and the motivation to respond, with the latter effect being most pronounced when high effort is required (Aberman and Salamone, 1999). Such findings demonstrate that NAcc DA regulates the motivation for ("wanting") sweet-tasting stimuli (Nunes et al., 2013). In contrast, NAcc DA does not regulate appetite for homeostatic dietary need (Cousins and Salamone, 1994) or hedonic responding to ("liking") sweet stimuli (Smith et al., 2011). There is also interest in DA regulation of the motivation required under cognitively effortful conditions. For example, VTA DA projection to prefrontal cortex (PFC) has been proposed to maintain goaldirected behaviour when challenged by distracter stimuli (Cools et al., 2011; van Schouwenburg et al., 2010). Reversal learning involves changes in response-outcome contingency and requires inhibition of responding to a stimulus previously associated with reward i.e. inhibition of perseveration, and disinhibition of responding to a stimulus previously associated with non-reward i.e. suppression of learned irrelevance/non-reward. Serotonin in PFC inhibits perseveration in common marmoset (Clarke et al., 2004), and glutamate within orbital PFC suppresses learned irrelevance in a reversal test that separates perseveration and learned non-reward, in rat (Tait and Brown, 2007). Recently, a learned non-reward (LNR) test was described for mouse, allowing for the specific study of operant responding to a stimulus that previously had a negative valence (non-reward) and now has a positive valence (reward) in the absence of perseveration (Nilsson et al., 2012).

Nucleus accumbens DA also modulates goal-directed behaviour relative to unconditioned aversive stimuli. Dopamine is released acutely in the NAcc in response to electric footshock (Young et al., 1993) and social stress (Cabib and Puglisi-Allegra, 2012), for example. In the case of inescapable/uncontrollable stimuli, the initial increase in NAcc DA is followed by a decrease below pre-stress tonic levels (Cabib and Puglisi-Allegra, 2012). As with positive stimuli, NAcc DA appears to modulate both the response-outcome learning and motivational aspects of behaviour relative to aversive stimuli. In rat, depletion of NAcc DA leads to a deficit in operant lever pressing or two-way shuttling to avoid-escape footshock (McCullough et al., 1993; Wenzel et al., 2015). In DA-deficient mice in which DA expression could be reactivated region-specifically, restoration of DA signalling to both entire striatum and amygdala was necessary and sufficient to enable mice to learn two-way active avoidance (Darvas et al., 2011). Also in mice, DA depletion in VTA and substantia nigra pars compacta led to increased sensitivity to inescapable footshock, expressed as a response deficit in a lever-press escape test i.e. learned helplessness (Winter et al., 2007). With respect to aversive stimulus-stimulus learning, studied primarily using Pavlovian fear conditioning, conditioned stimuli (CS e.g. tone) that predict footshock stimulate DA release in 
the NAcc (Pezze and Feldon, 2004; Wenzel et al., 2015). Whether NAcc DA depletion affects CS fear conditioning or expression remains to be investigated (Pezze and Feldon, 2004).

The present study investigated the effects of NAcc DA depletion in a battery of behavioural tests for assessment of responding to positive- and negative-valence stimuli in mice. The tests used are given in Table 1, together with the outcome stimulus and type of effort required to attain it, as well as the mediating behavioural dimensions according to the terminology of the RDoC framework (Cuthbert and Insel, 2013). The first test was operant responding for gustatory reward on a progressive ratio schedule (PRS) of reinforcement (Ineichen et al., 2012). Mice learned the operant response-outcome association prior to 6OHDA administration, so that effects of NAcc DA depletion on approach motivation under physical effort could be investigated per se (Table 1). The second test was responding to operant stimuli with changing association with gustatory reward in a learned non-reward (LNR) test (Nilsson et al., 2012): mice were trained through a series of simple + LNR discrimination stages prior to 6-OHDA administration. Then the effects of NAcc DA depletion were investigated on a final simple + LNR discrimination stage, the latter providing a test of cognitive effort and the maintaining of approach motivation when the association between an operant stimulus and reward shifts from negative to positive (Table 1). The third test was a learned helplessness (LH) test (Pryce et al., 2012), conducted after NAcc DA depletion. Mice were pre-exposed to inescapable footshock, followed by a two-way footshock escape test. The latter provided a test of motivation to escape aversion (safety motivation) requiring physical effort and cognitive perception of response-outcome contingency (Table 1). The fourth test was a treadmill running test (Azzinnari et al., 2014), conducted after NAcc DA depletion. Mice learned that forward movement on the treadmill resulted in operant avoiding or escaping of footshock, using a slow speed. In the subsequent test conducted at a higher speed, running time provided a measure of motivation to avoid-escape aversion (safety motivation) under physical effort (Table 1). Whilst behaviour in each of these four tests was motivated by different stimulus outcomes and required different forms and degrees of effort to attain that outcome, each was based on operant learning. In contrast, the fifth test was auditory CS-footshock fear conditioning, based on stimulus-outcome (Pavlovian) learning (Table 1). The behavioural effects of 6-OHDA depletion of NAcc DA were investigated in each of these tests. In addition, because 6-OHDA infusion onto NAcc also resulted in DA depletion in PFC, and given the importance of PFC in regulating cognitive aspects of goaldirected behaviour, effects of 6-OHDA infusion onto PFC were also studied directly for specific tests. This was the case for the LNR test where re-learning operant stimulus valence was required, and for the $\mathrm{LH}$ test because the PFC is critical to processing stimulus control and loss thereof (Amat et al., 2008). To our knowledge, this is the first study of the effects of 
NAcc DA depletion in the PRS and CS fear conditioning tests in mice, and the first to investigate effects of NAcc DA depletion in the LNR test and the treadmill test in any species.

(TABLE 1 ABOUT HERE)

As noted above, rat 6-OHDA studies have contributed most to current understanding of DA regulation of behaviour. However, there is increasing emphasis on the mouse as a study species. For example, chronic social defeat stress in mice has been shown to reduce reward-directed behaviour (Chaudhury et al., 2013; Tye and Deisseroth, 2012) and safety motivation relative to aversive stimuli (Azzinnari et al., 2014), and optogenetics has been applied to stimulate VTA DA neurons and reverse some of these effects (Chaudhury et al., 2013; Tanaka et al., 2012; Tye et al., 2013). Many such mouse studies are being guided by extrapolation of the findings obtained with NAcc 6-OHDA DA depletion in rat. Therefore, it is important to establish the behavioural effects of 6-OHDA DA depletion in mouse per se. Given the putative importance of NAcc DA in modulating motivation relative to positive- and negative-valence stimuli and the prevalence of motivation pathologies in psychiatric disorders, operant behavioural tests of effortful motivation are of particular relevance.

\section{MATERIALS AND METHODS}

Animals

The study was conducted with male C57BL/6J mice (Janvier Labs, Saint-Berthevin, France) aged 10 weeks and weighting $26.1 \pm 2.0 \mathrm{~g}$ at the time of surgery. Mice were maintained in pairs in type $2 \mathrm{~L}$ cages and on a reversed 12:12 h light-dark cycle (lights off at 07:00 h) in an individually-ventilated caging system, with temperature at $20-22^{\circ} \mathrm{C}$ and humidity at $50-60 \%$. The standard diet was complete pellet (Provimi, Kliba Ltd, Kaiseraugst, Switzerland) and water, both available continuously and ad libitum unless for experimental reasons as stated below. All procedures were conducted under a permit for animal experimentation (No. 170/2012) issued by the Veterinary Office, Zurich, Switzerland, in accordance with the Animal Protection Act (1978) Switzerland.

Injection of 6-hydroxydopamine (6-OHDA)

At 30 min prior to injection of 6-OHDA or vehicle, mice received i.p. injections of desipramine hydrochloride (35 mg/kg, Sigma-Aldrich) and escitalopram oxalate $(5 \mathrm{mg} / \mathrm{kg}, \mathrm{H}$. Lundbeck A/S, Valby, Denmark) to block 6-OHDA uptake by noradrenaline and serotonin neurons, respectively (Tanaka et al., 2012; Thiele et al., 2012). Mice were anaesthetised with a cocktail of fentanyl $0.04 \mathrm{mg} / \mathrm{kg}$, midazolam $4 \mathrm{mg} / \mathrm{kg}$ and medetomidine $0.4 \mathrm{mg} / \mathrm{kg}$, i.p.. Using a stereotaxic frame (WPI, Berlin, Germany) and $10 \mu$ syringe (NanoFil, WPI) equipped with a 33G needle (WPI), mice received bilateral injections of 6-OHDA hydrochloride (Sigma- 
Aldrich) or vehicle in NAcc, mPFC or caudate putamen (CPu). 6-OHDA was dissolved in $0.9 \%$ saline containing $0.02 \%$ ascorbic acid (AA). Coordinates, established using a mouse brain atlas (Franklin and Paxinos, 2008) and pilot injections of methylene blue, were, relative to bregma: for NAcc (shell/core) AP +2.0, ML \pm 0.7 , DV $-4.6 \mathrm{~mm}$; for $\mathrm{mPFC}$ (prelimbic/infralimbic/medial orbital) $\mathrm{AP}+2.4, \mathrm{ML} \pm 0.3$, DV $-2.4 \mathrm{~mm}$; for $\mathrm{CPu} A P+1.0, \mathrm{ML}$ \pm 2.0 , DV -3.0 mm. Injection parameters for 6-OHDA were, for NAcc $1.5 \mu \mathrm{g}$ or $2 \mu \mathrm{g} / 0.5 \mu \mathrm{l} / 2.5$ $\mathrm{min}$, for $\mathrm{mPFC} 1.5 \mu \mathrm{g} / 0.2 \mu \mathrm{L} / 2 \mathrm{~min}$, and for $\mathrm{CPu} 3.5 \mu \mathrm{g} / 1.0 \mu \mathrm{L} / 10 \mathrm{~min}$, and the same volume and rate were used for respective vehicle injections (0.02\% AA in saline). The 6-OHDA amount and volume injected were adjusted according to region size and basal DA level (see Results). The needle was left in place for a further $3 \mathrm{~min}$ to allow tissue diffusion, before being retracted slowly. A period of 10-12 days, sufficient for mouse post-surgery recovery and for degeneration of DA fibres (Stott and Barker, 2014), was allowed between injection and behavioural testing. Body weight was measured on days 1-10 post-surgery.

\section{Behavioural testing}

Operant tests using gustatory reward stimuli

Apparatus. For the progressive ratio schedule (PRS) and learned non-reward (LNR) experiments, training and testing were conducted using operant chambers (TSE Systems $\mathrm{GmbH}$, Bad Homburg, Germany) details of which are given elsewhere (Ineichen et al., 2012). Briefly, operant nose-poke ports detected mouse nose poke responses via an infra-red beam, and port position and number changed according to the test (PRS or LNR). Sugar pellets (14 mg, Dustless Precision Pellets, TSE Systems $\mathrm{GmbH}$ ) were delivered singly into the feeder port, which was situated adjacent to the single nose-poke port in the PRS test and in the wall opposite the two nose-poke ports in the LNR test. Pellet delivery was signalled by a tone from a speaker. Pellet retrieval was detected via infra-red beam.

Restricted feeding protocol. For 5 days, daily body weight and food intake were measured to obtain mean baseline values per mouse. Beginning one week before and continuing during the operant training phases of the PRS and LNR experiments, mice were food restricted and kept at $90-95 \%$ of their free-feeding (baseline) body weight, to ensure motivation for operant training.

Progressive ratio schedule (PRS) test

Naive mice $(\mathrm{N}=24)$ were initially trained to nosepoke into a single port to obtain a sucrose pellet under a fixed ratio 1 (FR1) schedule. Mice required 8-12 sessions to achieve operant learning, defined as 2 consecutive sessions with $\geq 30$ pellets earned at FR1. For PRS testing, mice were returned to $100 \%$ baseline body weight; this was to reduce appetite and thereby increase test sensitivity to detecting motivation for the sweet taste rather than 
calorific content, of sucrose pellets. Mice were then given 3 sessions of PRS testing and the mean score of the last two sessions was used to counter-balance allocation to experimental groups, NAcc Vehicle vs 6-OHDA. The PRS test parameters were: required number of nosepokes on first trial $=1$, number of consecutive trials for which the ratio remained constant $=5$, and number of nose-pokes by which the ratio increased per increment $=3$, e.g. reward ratio on trials $1-5=1$ response, on trials $6-10=4$, on trials $11-15=7$, and on trial $16-20=10$, and so on. The break point, i.e. minimum time without at least 1 response, that resulted in end of the session was $600 \mathrm{~s}$, and maximum session duration was 40 min. After surgery $+10-12$ days, mice, weighing $100 \%$ baseline body weight (104 $\pm 3 \%)$, were given the PRS test. The measures of interest were: cumulative number of pellets earned and ratio attained at 10, 20, 30 and 40 min after test onset, overall mean time between collection of pellet $n$ and the first operant response for pellet $n+1$ (post-reinforcement pause, PRP), and absolute peak response rate $(P R R)$ calculated as the highest overall response rate within a ratio and expressed as responses/min (Bezzina et al., 2008).

\section{Learned non-reward (LNR) test}

The LNR test was based on that described by (Nilsson et al., 2012). Naive mice, $\mathrm{N}=19$ in NAcc experiment and N=25 in mPFC experiment, were kept at 90-95\% baseline body weight throughout LNR testing. Details of operant training for this test are given in Supplementary Material. Briefly, mice were trained to initiate each trial by one nosepoke into the feeder port, which illuminated an operant nose-poke port in the opposite, stimulus wall; one response in the operant port activated signalled delivery of a sucrose pellet into the feeder port, which the mouse returned to and retrieved the pellet. The criterion for completion of training was 2 consecutive sessions with $\geq 49$ pellets earned. There were three spatial locations (left, middle, right) in the stimulus wall. The first test stage was two-choice spatial discrimination (SD): following trial initiation, the subject had to choose between two operant nose-poke ports whilst a blank panel occupied the third location. A response in the correct operant port led to delivery of a sucrose pellet in the feeder port and an incorrect response led to a $5 \mathrm{~s}$ timeout. Mice were allowed $10 \mathrm{~s}$ to initiate a trial and $6 \mathrm{~s}$ to make a choice response. The SD stage consisted of 70 trials divided into seven 10-trial blocks; SD learning criterion was nine correct responses within any 10-trial block, and if the subject did not attain criterion the SD stage was repeated the next day. On the day after attaining SD criterion, the second stage, learned non-reward (LNR), was presented: the incorrect operant port location at SD became the correct port, the previously correct operant port was replaced by the blank panel, and the blank panel was replaced by an operant port that became the new incorrect port. Number of trials, times allowed for trial initiation and choice responding, and learning criterion were identical to those at the SD stage. At the LNR stage, the subject must 
overcome no reinforcement-avoid behaviour and acquire reinforcement-approach behaviour at the previously incorrect/now correct operant port, without possibility to perseverate at the previously correct port (Nilsson et al., 2012). Measures of interest for SD and LNR were: omissions to initiate a trial (OIT), omissions to make a choice response (OR), incorrect choice response (IR), the sum of OIT, OR and IR, referred to as total errors (TE), and correct choice responses (CR). Prior to 6-OHDA infusion, mice were tested on three stages of SD+LNR so that the effects of DA depletion could be assessed against a stable baseline of acquired SD and LNR behaviour. Between completion of LNR and the subsequent SD stage, mice were given one session with only the central operant port (re-baselining). Total errors in the third LNR stage were used to counter-balance allocation to Vehicle and 6-OHDA groups. After surgery $+10-12$ days, mice, weighing 90-95\% baseline body weight (Expt NAcc $92 \pm 4$ $\%$; Expt mPFC $93 \pm 5 \%$,) were tested on the fourth, test stage of SD+LNR.

Operant tests using footshock aversive stimuli Learned helplessness (LH) test

The LH test was conducted using a fully-automated apparatus (Multi Conditioning System, TSE Systems GmbH, Bad-Homburg, Germany) details of which are given in (Pryce et al., 2012). Briefly, an arena was positioned on an electrifiable grid and contained a central divider with an opening ("gate") via which mice could transfer from one side of the arena to the other. The test was based on the evidence that pre-exposure of mice to inescapable (uncontrollable) footshocks in this context leads to a subsequent deficit in two-way escape behaviour to the same stimulus in the same context, relative to mice pre-exposed to the same amount of escapable (controllable) footshock and to mice without footshock preexposure i.e. a validated specific LH effect (Pryce et al., 2012). In the present experiment, only the inescapable condition was used, to assess whether NAcc or mPFC DA depletion affected (1) responses to inescapable footshock and (2) responses to the shift from inescapable to escapable footshock. (Whether DA depletion effects were specific to preexposure to inescapable stimuli or also altered responses to pre-exposure to escapable stimuli was not tested.) Naive mice were allocated randomly to 6-OHDA and Vehicle groups (NAcc experiment $\mathrm{N}=27$, mPFC experiment $\mathrm{N}=24$ ). After surgery $+10-12$ days (day 1 ), mice were placed in the arena for 15-min without footshock to habituate them to the two-way arena and assess locomotor activity (activity test). On days 2-4, Inescapable footshock exposure, mice received 24 inescapable footshock (IS) trials/day, at $0.15 \mathrm{~mA}$; footshock duration was variable, with mean of $3.5 \mathrm{~s}, 2.7 \mathrm{~s}$ and $3.3 \mathrm{~s}$ on days 2,3 and 4 , respectively (maximum per trial footshock duration was $5 \mathrm{~s}$ on each day); with a variable inter-trial interval (ITI) of $50 \pm 40 \mathrm{~s}$. On day 5 , Escape test, mice received 30 escapable footshock (ES) trials at $0.20 \mathrm{~mA}$, maximum footshock duration of $5 \mathrm{~s} / \mathrm{trial}$, and ITI $50 \pm 40 \mathrm{~s}$. The following measures 
were calculated for the Escape test: total escape failures, mean escape latency, mean locomotor activity during ITI (arbitrary units/min, a.u./min), mean \% time spent freezing during ITI (freezing defined as zero a.u. moved for at least $2 \mathrm{~s}$ ), and distance moved during footshock (footshock reactivity, a.u./s).

In the activity test specifically, NAcc 6-OHDA mice exhibited decreased locomotion (see Results). In order to investigate whether this was associated with an anxiogenic effect of DA depletion in a novel environment, an additional experiment was conducted in which mice were first given an activity test in the two-way arena, on the following day received NAcc 6OHDA $(\mathrm{N}=10)$ or Vehicle $(\mathrm{N}=10)$ infusion, and were then given further activity tests in the familiar arena at 14 and 15 days post-surgery. Because NAcc 6-OHDA led to a moderate reduction in $\mathrm{CPu} \mathrm{DA}$ in the learned helplessness experiment, an additional control experiment was conducted in which 6-OHDA $(\mathrm{N}=4)$ or Vehicle $(\mathrm{N}=5)$ was injected on the $\mathrm{CPu}$ and effects on behaviour in the activity test were assessed.

\section{Treadmill test}

The same mice that were studied in terms of NAcc DA depletion effects in the LH test were used for this experiment, with an interval of 2 days. The treadmill test requires the mouse to run on an inclined $\left(5^{\circ}\right)$ plane to avoid or escape an electrified grid (Azzinnari et al., 2014). The test is suitable to detect changes in two states, although not concurrently: absolute level of effort to avoid-escape punishment - if this level is exceeded by the treadmill speed the subject will receive the maximum footshock amount shortly after test onset; cumulative level of effort to avoid-escape punishment - cumulative footshock will increase gradually but exponentially across time. On experimental day 1 (training), mice were placed on the treadmill for $2 \mathrm{~min}$ at a speed of $0 \mathrm{~cm} / \mathrm{s}, 5 \mathrm{~min}$ at $15-20 \mathrm{~cm} / \mathrm{s}$ at $1 \mathrm{~min}$ increments, and $5 \mathrm{~min}$ at $20 \mathrm{~cm} / \mathrm{s}$. Total number and duration of footshocks were scored automatically; maximum cumulative footshock duration was $20 \mathrm{~s}$ and training was terminated if this was reached. On day 2, a pre-test session consisted of $2 \mathrm{~min}$ at $0 \mathrm{~cm} / \mathrm{s}$ and $5 \mathrm{~min}$ at $20 \mathrm{~cm} / \mathrm{s}$. This was followed immediately by the test session: $20 \mathrm{~min}$ at $23 \mathrm{~cm} / \mathrm{s}$, with the session stopped earlier if cumulative footshock duration reached $10 \mathrm{~s}$. Test measures were running time at $23 \mathrm{~cm} / \mathrm{s}$ (maximum $20 \mathrm{~min}$ ) and cumulative footshock duration (maximum $10 \mathrm{sec}$ ).

\section{Pavlovian CS-footshock fear conditioning test}

For this test of aversive stimulus-stimulus conditioning the same apparatus was used as for the LH test. Naive mice $(\mathrm{N}=19)$ were allocated randomly to NAcc 6-OHDA and Vehicle groups. After surgery $+10-12$ days (day 1 ), mice were placed on the grid in the arena (without central gate) for $15 \mathrm{~min}$ without footshocks to assess locomotor activity and habituate mice to the arena (context). On day 2 (Conditioning) mice were placed back in the 
arena and exposed to 6 trials of $20 \mathrm{~s}$ tone $(5 \mathrm{kHz}, 85 \mathrm{~dB}$, conditioned stimulus, CS) the final $2 \mathrm{~s}$ of which were contiguous with an inescapable footshock of $0.20 \mathrm{~mA}$ (unconditioned stimulus, US) and with ITI of $120 \mathrm{~s}$. On day 3 (Expression test) mice were returned to the arena for a 20 -min context test $(20 \times 1$-min bins), followed immediately by a CS test in the same context comprising $12 \times 30 \mathrm{~s}$ CS with ITI of $90 \mathrm{~s}$. The test measure was \% time spent freezing during CS or ITI trials (Cathomas et al., 2015; Fuertig et al., 2015).

Hot plate pain test

As an independent assessment of effects of NAcc DA depletion on pain sensitivity, a hot plate test was conducted in mice studied in the learned helplessness + treadmill experiment and in mice studied in the fear conditioning experiment, with an inter-test interval of 1 day. The hot plate test was conducted using a programmable thermoelectric heating plate (Teca, Chicago IL, USA) set at $50^{\circ} \mathrm{C}$ (Pryce et al., 2012). The latency (s) until first occurrence of one of the following behaviours was scored: licking a forepaw, licking a hind paw, lifting a hind paw, jumping. The maximum test duration was $60 \mathrm{~s}$.

Ex vivo determination of brain tissue monoamine levels

At 1-2 days after completion of a behavioural experiment, the fresh brain was collected, frozen on powdered dry-ice and stored at $-80^{\circ} \mathrm{C}$. Frozen brains were sectioned coronally at $1.0 \mathrm{~mm}$ intervals (Azzinnari et al., 2014). The NAcc, mPFC, CPu and amygdala (Amyg) were identified using a mouse brain atlas (Franklin and Paxinos, 2008) and micro-dissected bilaterally using a brain punch (Azzinnari et al., 2014) and the two punches per region were processed together. Mean total tissue weights per region were: $\mathrm{NAcc}=1.7 \mathrm{mg}, \mathrm{mPFC}=1.3$ $\mathrm{mg}, \mathrm{CPu}=1.3 \mathrm{mg}$, Amyg = $1.6 \mathrm{mg}$.

HPLC-ED for DA and 5-HT. For tissue homogenization, $100 \mu \mathrm{l}$ (mPFC, Amyg), $250 \mu \mathrm{l}$ (NAcc) or $300 \mu \mathrm{l}(\mathrm{CPu})$ ice-cooled perchloric acid $(0.4 \mathrm{M})$ were added to each sample. Ultrasonication was conducted for $5 \mathrm{~s}$ at $30 \%$ power (VibraCell, VCX130PB, Sonics and Materials, Newtown CT, USA), followed by centrifugation at $16,000 \times \mathrm{g}$ for $10 \mathrm{~min}$ at $4^{\circ} \mathrm{C}$. The supernatant was passed through a $0.22 \mu \mathrm{m}$ filter (Minisart RC4, Sartorius, Göttingen, Germany) and kept on ice until analysis. High performance liquid chromatography (HPLC) and electrochemical detection (ED) were conducted for DA and 5-HT and their respective major metabolites, dihydroxyphenylacetic acid (DOPAC) and 5-hydroxyindoleacetic acid (5HIAA), according to (Oeckl et al., 2012). Briefly, isocratic separation of DA and 5-HT was carried out with a reversed-phase C18 column (YMC-Pack ODS-AQ, 100×2.1 mm, S-3 $\mu \mathrm{m}$, YMC Europe). Homogenates $(20 \mu \mathrm{l})$ were injected onto the HPLC system using an autosampler (ASI-100T). The mobile phase consisted of $1.7 \mathrm{mM}$ 1-octanesulfonic acid sodium salt, $1.0 \mathrm{mM} \mathrm{Na}{ }_{2}$ EDTA $\times 2 \mathrm{H}_{2} \mathrm{O}, 8.0 \mathrm{mM} \mathrm{NaCl}, 100 \mathrm{mM} \mathrm{NaH}_{2} \mathrm{PO}_{4} \times 2 \mathrm{H}_{2} \mathrm{O}(\mathrm{pH} 3.8)$, 
mixed with $9.3 \%$ acetonitrile, and was delivered at a flow rate of $0.4 \mathrm{ml} / \mathrm{min}$. For ED, an electrochemical flowcell with glassy carbon electrode and ISAAC $\mathrm{Ag} / \mathrm{AgCl}$ reference electrode (VT-03 or SenCell, Antec) was used. Concentrations of monoamines and metabolites were calculated using external-standard calibration and expressed as $\mathrm{ng} / \mathrm{mg}$ brain tissue. For the NAcc PRS and LNR experiments, the flowcell used was model VT-03, and for all subsequent experiments the flowcell used was model SenCell. Nucleus accumbens DA concentrations obtained with the VT-03 were lower than those obtained with the SenCell and the latter also allowed for a lower limit of quantification (LLOQ) for DA, which was particularly important for mPFC samples (see Table 2). In the absence of any alternative explanation, it is possible that these differences between experiments were attributable to the flowcell used.

Radioenzymatic assay for noradrenaline. Following tissue homogenization (see above), NAcc, mPFC and Amyg samples were further diluted (1:10, 1:1 and 1:5, respectively) in artificial cerebrospinal fluid (aCSF). A radioenzymatic assay for NA was used, as described previously ( $\mathrm{Lu}$ et al., 2008). This assay involves COMT-catalyzed Omethylation using $\left[{ }^{3} \mathrm{H}\right] \mathrm{S}$-adenosylmethionine as methyl donor, and separation of the resulting $\left[{ }^{3} \mathrm{H}\right]$ normetanephrine by thin-layer chromatography (TLC).

Immunohistochemistry for tyrosine hydroxylase

In addition to HPLC-ED quantification of DA tissue levels, 6-OHDA depletion of DA fibre terminals in NAcc (and surrounding regions) was also assessed qualitatively using tyrosine hydroxylase immunohistochemistry. In an additional cohort of mice, following NAcc 6-OHDA $(\mathrm{N}=10)$ or Vehicle $(\mathrm{N}=10)$ infusion +12 days, mice were deeply anaesthetized with pentobarbital and transcardially perfused with phosphate-buffered saline (PBS, $\mathrm{pH} 7.4)$ and fixative (4\% paraformaldehyde (PFA) in PBS). Brains were post-fixed over-night in 4\% PFA, and cryoprotected in $30 \%$ sucrose for $48 \mathrm{~h}$. Brains were frozen on powdered dry ice and cut at $40 \mu \mathrm{m}$ with a microtome (Zeiss). Brain sections were collected in antifreeze solution and stored at $-20^{\circ} \mathrm{C}$ until analysis. Free-floating sections were washed with PBS, quenched with $3 \% \mathrm{H}_{2} \mathrm{O}_{2}$ for $15 \mathrm{~min}$, blocked with normal goat serum and incubated o/n at $4^{\circ} \mathrm{C}$ with a mouse anti-tyrosine hydroxylase antibody (1:1000; Santa Cruz Biotechnology), followed by $2 \mathrm{~h}$ RT incubation with a biotinylated goat anti-mouse secondary antibody (1:500; Millipore). Sections were then incubated with $1 \%$ avidin-biotin peroxidase complex (Vectastain ABC kit, Vector) for $30 \mathrm{~min}$ at RT. Staining was visualized using diaminobenzidine (DAB) solution. NAcc was identified using the mouse brain atlas (Franklin and Paxinos, 2008). Images were acquired using a brightfield microscope (Zeiss, Axiovert).

Statistical analysis 
Statistical analysis of 6-OHDA lesion effects on behaviour and brain monoamine content was conducted using SPSS (version 20, SPSS Inc., Chicago IL, USA). In most cases an unpaired $t$-test was performed. Prior to conducting a t-test, Levene's test for equality of variances was conducted; in case of non-equal variances the corresponding $t$-test was used and degrees of freedom adjusted accordingly. Analysis of variance (ANOVA) was conducted in cases of repeated measures, with a between-subject factor of group (6-OHDA, Vehicle) and a within-subject factor of test phase (e.g. PRS test, LH test, fear conditioning test). Where appropriate, ANOVA post hoc testing was conducted using the Bonferroni procedure. Statistical significance was set at $p \leq 0.05$. Where an estimate of variance is given this is the standard deviation (SD).

\section{RESULTS}

Efficacy and specificity of 6-OHDA dopamine depletion

The ex vivo DA tissue levels in NAcc, CPu, mPFC and Amyg are given in Table 2. In the five experiments in which 6-OHDA lesioning targeted NAcc, 6-OHDA induced a marked reduction in NAcc DA (mean per experiment $=74-87 \%$ ). Off-target regions were selected for specificity control and because their DA function could be relevant to the behavioural processes under study. In CPu, DA was increased in the PRS test, decreased in the learned helplessness test + treadmill test, and unchanged in the other three experiments. In mPFC, where baseline (Vehicle) DA levels were markedly lower than in other regions, NAcc 6-OHDA reduced mPFC DA in each experiment. There was no effect of NAcc 6-OHDA on Amyg DA levels, as assessed in two experiments. In a control experiment in which 6-OHDA was injected onto $\mathrm{CPu}$, it induced an almost complete (99\%) depletion of CPu DA; there was no effect on DA in NAcc or Amyg whist DA was reduced in mPFC. In the two experiments in which 6-OHDA lesioning targeted mPFC, 6-OHDA mice exhibited a marked reduction in mPFC DA (67$86 \%)$; DA depletion was specific to mPFC. Table 2 also provides the interval in days between 6-OHDA injection and brain collection for monoamine measurement. The interval was identical for all mice within each experiment, and varied between 11 and 24 days between experiments. There was no evidence that between-experiment differences in ontarget or off-target effects on DA levels were due to the interval between 6-OHDA injection and brain collection.

With regards to 5-HT (Table S1), across all experiments there was only one regionspecific case of decreased 5-HT and two region-specific cases of increased 5-HT, in 6OHDA mice. To assess the effect of NAcc or mPFC 6-OHDA lesion on NA levels, additional experiments were conducted (Table S2): NAcc 6-OHDA lesion did not affect NA levels in any region; $\mathrm{mPFC}$ 6-OHDA lesion led to increased NA in the mPFC and decreased NA in the NAcc. 
Nucleus accumbens 6-OHDA efficacy and specificity were also assessed qualitatively using tyrosine hydroxylase immunostaining of DA fibre terminals. Representative sections from Vehicle- and 6-OHDA-treated mice are given in Figure 1. In 6-OHDA mice, the tyrosine hydroxylase stain was markedly reduced in the medial-central core and the dorso-medial shell of NAcc in both hemispheres. One additional region that exhibited reduced staining in 6-OHDA mice was the extreme medial CPu. Of the ten 6-OHDA brains investigated, there were two cases where the tyrosine hydroxylase reduction was relatively small in the NAcc core-shell of one hemisphere.

\section{(FIGURE 1 ABOUT HERE)}

Physical effects of 6-OHDA dopamine depletion

Effects of NAcc, CPu or mPFC 6-OHDA injection on body weight (BW) were measured for days 1 to 10 after surgery. ANOVA was conducted for post-surgery BW expressed as a percentage of pre-surgery baseline $(=100 \%)$. Data for the NAcc learned helplessness + treadmill experiment are presented as a representative example of NAcc 6-OHDA experiments (Figure S1): There was a Group X Day (baseline, post-surgery days 1-10) interaction $\left(F_{(10,271)}=4.3, p<0.0005\right)$; post hoc analysis revealed that Vehicle mice recovered to baseline BW by day 4 whereas 6-OHDA mice recovered by day 8 only, and that $\%$ BW was lower in 6-OHDA compared to Vehicle mice on days 1-5. For the CPu 6-OHDA control experiment, there was a main effect of Day $\left(F_{(10,70)}=25.6, p<0.0005\right)$ but no effect involving Group ( $\mathrm{p} \geq 0.87$ ); post hoc analysis revealed that both groups recovered baseline BW by day 2 (data not shown). For the mPFC 6-OHDA learned helplessness experiment, there was a main effect of Day $\left(F_{(10,220)}=8.8, p<0.0005\right)$ but no effect involving Group $(p \geq 0.56)$; post hoc analysis revealed that both groups recovered baseline BW by day 4 (data not shown).

In the following sections the behavioural effects of 6-OHDA injection on NAcc, CPu or mPFC in specific tests are reported. Whilst a number of interesting behavioural deficits were induced, the evidence indicates that these were absolute effects of DA reduction, and in 6OHDA mice there was no evidence for significant correlation between the extent of depletion and the behavioural effect observed.

Operant tests using gustatory reward stimuli

Progressive ratio schedule (PRS) test

In the PRS test, the effect of 1.5 or $2.0 \mu \mathrm{g} 6-\mathrm{OHDA}$ injection in the NAcc on reward motivation under effortful conditions was investigated. Following operant training and prior to surgery, mice were given three PRS tests, and for group allocation were counter-balanced on total number of pellets earned (Vehicle: $47.9 \pm 0.3,1.5 \mu \mathrm{g}: 45.8 \pm 0.3,2 \mu \mathrm{g}: 46.2 \pm 0.8$ $(p=0.48))$ and final ratio attained (Vehicle: $28.4 \pm 0.4,1.5 \mu \mathrm{g}: 27.4 \pm 0.4,2 \mu \mathrm{g}: 27.4 \pm 1.0$ $(p=0.62))$. For analysis of 6 -OHDA effects on cumulative number of pellets earned and PR 
ratio attained, the PRS test was divided into four 10-min blocks and ANOVA was conducted for Dose $X$ Time-block. For cumulative pellets earned there was a main effect of Dose $\left(F_{(2}\right.$, ${ }_{21}=4.20, p<0.03$; Fig. 2A); post hoc analysis revealed that mice injected with $2 \mu \mathrm{g}$ 6-OHDA earned less pellets than Vehicle mice $(p<0.04)$. There was also a main effect of Dose for $P R$ ratio attained $\left(F_{(2,21)}=3.9, p<0.04\right.$; Fig. $\left.2 B\right) ; 2 \mu \mathrm{g} 6$-OHDA mice attained a lower ratio than Vehicle mice $(p<0.04)$. The reduced motivation of NAcc DA-depleted mice was also evident in mean post-reinforcement pause $(\mathrm{PRP})\left(\mathrm{F}_{(2,21)}=15.4\right.$, p<0.0005; Fig. $\left.2 \mathrm{C}\right)$ with both $1.5 \mu \mathrm{g}$ and $2 \mu \mathrm{g}$ 6-OHDA mice exhibiting higher mean PRP than Vehicle mice, and in peak response rate $(P R R)\left(F_{(2,21)}=3.5, p<0.05\right.$; Fig. $\left.2 D\right)$ which was lower (and occurred at a lower ratio) in $2 \mu \mathrm{g} 6$-OHDA mice than in Vehicle mice. In all subsequent NAcc experiments, $2 \mu \mathrm{g}$ 6-OHDA specifically was used.

\section{(FIGURE 2 ABOUT HERE)}

Learned non-reward (LNR) test

The LNR test was used to investigate effects of 6-OHDA NAcc or mPFC injection on responding to operant stimuli with shifting association with gustatory reward. Mice were tested on three consecutive stages of both simple (SD) and learned non-reward (LNR) discrimination (SD+LNR 1-3) prior to DA depletion, and therefore any effects of 6-OHDA could not be due to impaired operant task acquisition. In the NAcc experiment, task acquisition was indicated by improved performance across successive stages. For example, for total errors there was a main effect of Stage for both simple discrimination $\left(F_{(2,54)}=3.7\right.$, $p<0.04)$ and learned non-reward $\left(F_{(2,38)}=4.0, p<0.03\right)(F i g .3 A)$; the decrease in total errors across stages indicated that mice learned rule-switching (Nilsson et al., 2012; Tait and Brown, 2007). The total error scores at LNR3 were used to counterbalance allocation of mice to NAcc 6-OHDA and Vehicle groups. At the post-treatment simple discrimination stage (SD4), there was no effect of NAcc 6-OHDA on any measure, e.g. total errors ( $p=0.37$, Fig. $3 \mathrm{~B})$. In contrast, NAcc 6-OHDA did impair behaviour at the post-treatment learned nonreward stage (LNR4) (Fig. 2B): relative to Vehicle mice, 6-OHDA mice exhibited increased omissions to initiate a trial $\left(t_{(9.5)}=-2.3, p<0.05\right)$, increased incorrect choice responses $\left(t_{(17)}=-\right.$ $3.2, p<0.005)$ and increased total errors $\left(t_{(12.3)}=-2.8, p<0.02\right)$. There was no effect on omissions to make a choice response $(p<0.2)$ or correct choice responses $(p<0.6)$.

In the mPFC experiment, as for NAcc, performance improved across successive stages of SD+LNR 1-3 testing, e.g. total errors decreased across stages of simple discrimination $\left(F_{(2,29)}=17.8, p<0.0005\right)$ and learned non-reward $\left(F_{(2,29)}=6.9, p<0.01\right)$. At the post-treatment simple discrimination stage (SD4) there was no effect of mPFC 6-OHDA on any measure (Table 3 ). In contrast to the NAcc experiment, there was also no effect of mPFC 6-OHDA on behaviour at the post-treatment learned non-reward stage (LNR4) (Table $3)$. 
(FIGURE 3 ABOUT HERE)

(TABLE 3 ABOUT HERE)

Operant tests using footshock aversive stimuli

Learned helplessness (LH) test

The learned helplessness test was used to investigate effects of NAcc or mPFC 6OHDA DA depletion on responsiveness to inescapable aversion and subsequent motivation to escape aversion (safety motivation) requiring physical effort and cognitive perception of response-outcome contingency. Following surgery and recovery, an activity test, three inescapable footshock pre-exposure sessions and an escape test, were conducted on consecutive days. In the NAcc experiment, in the activity test, 6-OHDA led to a decrease in locomotion $\left(\mathrm{t}_{(25)}=3.7, \mathrm{p}<0.001\right.$, Fig. $\left.4 \mathrm{~A}\right)$ and an increase in \% time freezing (Vehicle: $3.2 \pm$ $1.5 \%, 6-$ OHDA $\left.6.3 \pm 2.5 \%, \mathrm{t}_{(25)}=-3.8, \mathrm{p}<0.001\right)$. Mice were then exposed to three daily sessions of inescapable footshock: during the final session there was no effect of 6-OHDA on locomotor activity (Vehicle: $4617 \pm 1148$ a.u./min, 6-OHDA $3717 \pm 1291$ a.u. $/ \mathrm{min}, \mathrm{p}=0.08$ ), but 6-OHDA mice did exhibit increased mean \% time freezing (Vehicle: $10.8 \pm 5.3 \%$, 6OHDA $\left.18.7 \pm 12.0 \%, \mathrm{t}_{(25)}=3.4, \mathrm{p}<0.03\right)$. In the Escape test on the following day, there was no effect of 6-OHDA on locomotor activity ( $p=0.46$, Fig. 4B) or \% time freezing (Vehicle: 11.8 $\pm 5.3 \%, 6-$ OHDA $13.6 \pm 7.9 \%, p=0.49$ ). There were effects of 6-OHDA in terms of an increased mean latency to escape $\left(t_{(17.8)}=-2.1, p<0.05\right.$, Fig. $\left.4 \mathrm{C}\right)$ and increased number of escape failures $\left(t_{(25)}=-2.2, p<0.05\right.$, Fig. 4D). Escape failures were also analysed in blocks of 10 trials to investigate for DA-depletion learning effects: there was a main effect of group $\left(F_{(1}\right.$, $25)=4.6, p<0.05)$ and also of trial block $\left(F_{(1,50)}=4.4, p<0.02\right)$ but no interaction; whilst both 6 OHDA and Vehicle mice exhibited increased escape responses in trials 21-30 versus 1-10, indicating learning, the relative deficit in 6-OHDA mice persisted across the Escape test (Fig. $4 \mathrm{E})$. The escape deficit in 6-OHDA mice co-occurred with decreased footshock reactivity $\left(\mathrm{t}_{(23)}\right.$ $=2.5, p<0.05$, Fig. 4F, one outlier per group removed for analysis).

(FIGURE 4 ABOUT HERE)

We further investigated the findings of reduced locomotor activity and increased freezing by NAcc 6-OHDA mice in the activity test; this might indicate motor impairment or, given that the arena was novel during this session, increased anxiety/decreased motivation to explore novelty. An additional experiment (NAcc - Activity in Table 2) was conducted in which mice underwent an activity test prior to NAcc 6-OHDA lesion and were then re-tested in the familiar arena. Under these conditions there was no effect of NAcc 6-OHDA on locomotor activity $(p=0.17$, Fig. $S 2)$ or freezing $(p=0.85)$, supporting the interpretation that NAcc 6-OHDA increased anxiety in/decreased motivation to explore the novel arena, rather than affecting locomotion per se. 
Given that 6-OHDA mice in the NAcc - learned helplessness experiment exhibited a moderate decrease in CPu DA levels (Table 2), the effects of targeted CPu DA depletion in the activity test were studied in a separate cohort. An almost complete CPu DA depletion (CPu - Activity in Table 2) led to a 40\% decrease in locomotion (Vehicle: $8501 \pm 1802$ a.u./min, 6-OHDA $4825 \pm 1558$ a.u./min, p<0.01). This compared with a $25 \%$ decrease in locomotion in the activity test in NAcc 6-OHDA mice exhibiting the moderate off-target $\mathrm{CPu}$ DA effect and marked NAcc DA depletion (Fig. 4A).

In the mPFC experiment, in the activity test there was no effect of 6-OHDA on locomotor activity or \% time freezing (Table 4). During the final session of inescapable footshock, there was again no effect on locomotor activity or \% time freezing (Table 4). Also in the Escape test, mPFC DA depletion was without any behavioural effects, on locomotor activity, mean \% time freezing, escape failures, mean escape latency, or footshock reactivity.

(TABLE 4 ABOUT HERE)

Treadmill test

In the treadmill test, using the same mice as studied in the learned helplessness paradigm two days previously, the effect of NAcc 6-OHDA injection on motivation to avoidescape aversion (safety motivation) under physical effort was investigated. Mice were first exposed to the apparatus when it was stationary and then at walking speed, to enable them to acquire operant avoidance and escape responses. In the treadmill training session, there was no effect of 6 -OHDA on total footshock time ( $p=0.44$, Fig. $5 A)$. The next day, during the 5 -min pre-test session at a treadmill speed of $20 \mathrm{~cm} / \mathrm{s}$, there was a borderline non-significant increase in total footshock time in 6-OHDA mice (Vehicle: $5.8 \pm 8.4 \mathrm{~s}, 6$-OHDA: $12.0 \pm 8.3 \mathrm{~s}$, $\mathrm{p}=0.06$ ). In the treadmill test, conducted at a speed of $23 \mathrm{~cm} / \mathrm{s}$, the running time achieved was decreased in 6-OHDA compared to Vehicle mice $\left(t_{(25)}=3.7, p<0.001\right.$, Fig. 5B). Ten out of 13 Vehicle mice achieved the maximum running time of 20 min without accumulating $10 \mathrm{~s}$ of footshock, whereas this was the case in only 1 of $146-$ OHDA mice. Accordingly, total footshock time was higher in 6-OHDA than in Vehicle mice $\left(t_{(21.4)}=-4.1, p<0.001\right.$, Fig. $\left.5 \mathrm{C}\right)$.

\section{(FIGURE 5 ABOUT HERE)}

Pavlovian fear conditioning test

In the auditory tone-footshock (CS-US) fear conditioning test, the effects of NAcc 6OHDA on aversive stimulus-stimulus fear learning, measured as $\%$ time spent freezing, were investigated. During the CS-US conditioning session, there was a main effect of CS trialblock on $\%$ time freezing $\left(F_{(2,34)}=23.9, p<0.0005\right.$, Fig. $\left.6 \mathrm{~A}\right)$, with acquired freezing increasing continuously across trials. There was no main or interaction effect of 6-OHDA ( $p=0.54$, Fig. $6 \mathrm{~A})$. On the following day, consecutive expression tests were conducted for contextual and CS fear-freezing. There was no effect of NAcc 6-OHDA on \% time freezing in either the context test ( $p=0.32$; Fig. $6 B$ ) or the CS test $(p=0.51$, Fig. $6 C)$. Significant main effects of 
Trial in the context test $\left(F_{(6,102)}=14.0, p<0.0005\right.$, Fig. $\left.6 B\right)$ and CS trial in the CS test $\left(F_{(5,85)}=\right.$ 19.0, $p<0.0005$, Fig. 6C) indicated that freezing expression decreased as the test progressed, and that this occurred to a similar extent in 6-OHDA and Vehicle mice.

(FIGURE 6 ABOUT HERE)

Hot plate test

Nucleus accumbens 6-OHDA injection resulted in reduced reactivity to footshock in the learned helplessness test and the treadmill test. One possible explanation for these effects is reduced motivation to escape-avoid and another is analgesia. Therefore, in mice that had been studied in the NAcc learned helplessness + treadmill experiment and the NAcc fear conditioning experiment, the hot plate test was carried out to assess thermal pain sensitivity. There was no effect of NAcc 6-OHDA in mice studied in the learned helplessness test + treadmill test (response latency: Vehicle: $28.4 \pm 11.8 \mathrm{~s}, 6-\mathrm{OHDA}: 26.6 \pm 10.5 \mathrm{~s}$, $\mathrm{p}=0.68$ ) or in the fear conditioning test (Vehicle: $33.1 \pm 11.0 \mathrm{~s}, 6-\mathrm{OHDA}: 27.5 \pm 3.8 \mathrm{~s}$, $p=0.12$ ). Also in mice that had been studied in the mPFC 6-OHDA - learned helplessness experiment, there was no effect of 6-OHDA injection (Vehicle: $24.8 \pm 7.3 \mathrm{~s}, 6-\mathrm{OHDA}: 22.8 \pm$ $9.6 \mathrm{~s}, \mathrm{p}=0.25)$.

\section{DISCUSSION}

The overall aim of the present study was to investigate the effects of substantive 6-OHDAinduced DA depletion in the nucleus accumbens on reward and punishment processing in a novel mouse operant test battery, with the emphasis on identifying deficits relevant to motivation pathologies in psychiatric disorders. Bilateral DA/DA fibre depletion in the nucleus accumbens resulted in decreased: responding for gustatory reward on an effortful operant schedule (PRS test); responding to an operant stimulus recently associated with non-reward (LNR test); two-way escape responding to an aversive stimulus that was recently uncontrollable (LH test); one-way active avoidance-escape responding to an aversive stimulus under effortful conditions (treadmill test). NAcc DA depletion was without effect on stimulus-outcome processing (fear conditioning test). Owing to co-administration of drugs blocking their respective transporter proteins, neither serotonin nor noradrenaline were depleted by NAcc 6-OHDA lesion, indicating that the observed effects were consequent to DA depletion. Whilst NAcc 6-OHDA injection also resulted in off-target mPFC DA depletion, direct MPFC DA depletion did not recapitulate the behavioural effects of NAcc DA depletion when investigated in the LNR test and LH test.

Accumbens 6-OHDA lesioning impairs reward motivation under effortful or ambiguous conditions

The progressive ratio schedule with gustatory reward has been applied previously to study effects of NAcc 6-OHDA lesioning in rat: reduced motivation was demonstrated for 
high-effort PR schedules specifically (Hamill et al., 1999). To our knowledge the present study provides the first demonstration that also in mice NAcc 6-OHDA reduces motivation for gustatory reward under the high-effort conditions of a PR schedule. These effects were to some extent 6-OHDA dose-dependent, and the higher, more efficacious dose of $2 \mu \mathrm{g}$ per hemisphere was the specific dose used in all subsequent NAcc experiments. Mice were maintained at $100 \%$ baseline body weight (BW) for the PRS test, with the aim of maximising the palatable incentive value of sucrose pellets relative to their calorific value; rat studies also conducted PRS testing at or close to baseline BW e.g. (Hamill et al., 1999). Given that mice received extensive operant training and three PRS sessions prior to DA depletion, it is clear that the deficits in DA-depleted mice were not due to impaired task acquisition. Our findings support the hypothesis that NAcc DA modulates specific motivational processes underlying behaviour directed towards palatable reward (and probably also other reward categories), including behavioural activation, exertion of effort, appetitive behaviour, and sustained task engagement (Salamone and Correa, 2012). Sucrose (vs. water)-preference studies in rats demonstrate that NAcc DA depletion does not decrease reward wanting under non-effortful conditions (Berridge and Robinson, 1998). In human depression, patients do not differ from healthy controls in their reports of the intensity and pleasantness of sucrose (Dichter et al., 2010). However, using monetary reward, depressed patients exhibit reduced motivation to expend effort to obtain reward (Treadway et al., 2012). Given that mPFC DA was also decreased in the NAcc 6-OHDA-treated mice, and given that mPFC DA activity has been demonstrated to be associated with motivation for reward under effortful conditions (McGregor et al., 1996; Treadway et al., 2012), the observed effect cannot be attributed unequivocally to NAcc DA and future studies will be needed to clarify this.

The learned non-reward test deployed here was first described for mice, and relatively recently (Nilsson et al., 2012); the absolute and relative number of trials and errors to attain learning criteria at SD and LNR stages, as well as the rate of learning across stages, were similar in the present and original studies. Two-choice spatial discrimination (SD) requires acquisition of operant stimulus(OS)-reward (unconditioned stimulus, US) and OSnon-reward associations, and elicitation of appetitive and avoidance behaviours, respectively, by these two associations. The LNR contingency change requires relearning that the OS-non-reward association is now an OS-reward association and concomitant overcoming of avoidance due to learned non-reward (LNR). Accumbens 6-OHDA, administered after SD+LNR training, was without effect on both omission and commission errors during SD, indicating that the OS-US acquisitions and appropriate appetitive and avoidance behaviours were intact. At the LNR stage, NAcc 6-OHDA mice exhibited increases in both omission of trial initiations and commission of incorrect responses, each of which we interpret as indicative of excessive learned non-reward. That is, in the absence of 
normal NAcc DA levels, motivation - including behavioural activation, effort, approach - to engage with an OS with a recent association with non-reward was decreased. Mice received extensive operant training and three pre-depletion SD+LNR sessions, so the high LNR errors in DA-depleted mice were not due to impairment of task acquisition. In a rat study with a reversal learning (rather than LNR) test, DA depletion in dorsal striatum impaired reversal (O'Neill and Brown, 2007). Also in a rat reversal learning study, NAcc injection of $D_{1} R$ or $D_{2} R$ antagonist or $D_{1} R$ agonist were each without effect, and a $D_{2} R$ agonist impaired reversal learning (Haluk and Floresco, 2009). Excitotoxic lesion of the NAcc, particularly the core region, has been demonstrated to impair reversal between strategies and stimulus dimensions, as well as reversal between stimuli within a dimension; however, the use of excitotoxic lesion means that the observed effects cannot be attributed unequivocally to DA deficiency (Reading and Dunnett, 1991). In the original mouse LNR study, systemic serotonin $2 \mathrm{C}$ receptor $\left(5-\mathrm{HT}_{2 \mathrm{C}} \mathrm{R}\right.$ ) antagonism decreased $\mathrm{LNR}$ errors specifically (Nilsson et al., 2012). Given that $5-\mathrm{HT}_{2 \mathrm{C}} \mathrm{R}$ antagonism increases mesocorticolimbic DA function (Di Matteo et al., 2001), this performance-enhancing effect is relevant to the current findings that NAcc DA depletion leads to performance deficiency.

The PFC is a major projection region of the NAcc and is also important in reversal learning and other forms of behavioural flexibility (Clarke et al., 2004). In rat, the orbital PFC is important in simple reversal learning and the medial PFC in reversal learning between stimulus dimensions (Brown and Bowman, 2002). In the present study, mPFC 6-OHDA was without effect on either SD or LNR. Blockade of $D_{1} R$ or $D_{2} R$ in $m P F C$ in rat reduced behavioural flexibility; it acted primarily by increasing perseveration (Floresco et al., 2006), which is not tested in the LNR paradigm. It is therefore possible that in reversal learning tasks, mPFC mainly contributes to overcoming perseveration rather than to LNR (Allen and Leri, 2014; Son et al., 2013). Furthermore, neurotransmitters other than DA, in particular serotonin, may modulate mPFC-dependent cognitive flexibility (Clarke et al., 2004; van der Plasse and Feenstra, 2008). Taken together, the two mouse LNR experiments provide robust evidence that DA signalling in NAcc, and not in mPFC, is essential for adaptive motivation when the association between an operant stimulus and reward shifts from negative to positive.

Accumbens 6-OHDA lesioning impairs aversion-safety motivation under previously uncontrollable or effortful conditions

We established the learned helplessness effect paradigm for mice in order to have an objective test of aversive un/controllability for this species (Pryce et al., 2012). Following repeated sessions of matched escapable footshock (ES) or inescapable footshock (IS), when both groups are tested under ES conditions, IS mice exhibit more escape failures. This deficit 
in escape behaviour is underlain by decreased motor reactivity to the footshock, which we interpret as a motivational deficit, particularly given that pain sensitivity remains intact (Pryce et al., 2012). In the present study we restricted the experiment to the IS condition, and demonstrated that NAcc, but not mPFC, DA depletion resulted in increased escape failure concomitant with increased escape latency and decreased motor reactivity. In rat, 6-OHDA injection in the striatum led to increased operant escape failure in subjects exposed to IS, and the same effect was obtained when 6-OHDA was injected into the substantia nigra pars compacta (Winter et al., 2007). Also in rat, in the absence of prior IS, 6-OHDA NAcc DA depletion decreased operant (lever press) escape-avoid behaviour; furthermore, in intact subjects, performing this operant behaviour led to increased NAcc DA release (McCullough et al., 1993). Rats exposed to IS and exhibiting a high level of 2-way escape failure were characterised by a decrease in the proportion of active DA neurons in the VTA (Belujon and Grace, 2015). Therefore, in addition to chronic NAcc DA depletion impairing motivational processes that mediate engagement with reward, as evidenced in PRS and LNR tests, the current mouse learned helplessness findings add to the evidence that depleted NAcc DA also impairs murine motivational and learning processes mediating safety from punishment (Wenzel et al., 2015). Indeed, deficient motivation has been proposed to be one of the three major mediators of the learned helplessness effect (Maier and Seligman, 1976; Pryce et al., 2011), and the current evidence indicates that decreased NAcc DA contributes to this state. The other proposed major mediators of the learned helplessness effect are increased emotional responding to aversive stimuli perceived as uncontrollable, and decreased response-outcome expectancy (Maier and Seligman, 1976; Pryce et al., 2011). The proportion of time spent freezing provides a measure of emotionality in the LH paradigm: freezing was increased in NAcc DA depleted mice relative to control mice during IS preexposure but not during the escape test; freezing is also not increased in IS relative to ES intact mice (Pryce et al., 2012). By separating the escape test session into blocks of trials, we were able to analyse for learning effects on escape performance; both NAcc Vehicle and 6-OHDA mice made fewer escape failures as the session progressed, indicating that impaired operant learning did not underlie the deficit in the latter group. Future studies will need to ascertain whether these effects are specific to mice exposed to prior inescapable punishment, or whether the combination of depleted NAcc DA and escapable punishment also leads to motivation deficits.

This was the only experiment in which NAcc 6-OHDA resulted in reduced DA levels in $\mathrm{CPu}$; whilst the reduction was moderate, given the role of dorsal striatum in locomotion and motivation (Palmiter, 2008), it might have contributed to the behavioural effects observed. In a control experiment, the CPu was targeted with 6-OHDA to yield almost complete depletion of CPu DA, and locomotor activity was decreased, as would be expected (Kravitz et al., 
2010). However, the extent of the activity decrease (40\%) was not sufficient to suggest that the moderate off-target effects of NAcc 6-OHDA on CPu DA would account for the observed effects in the learned helplessness test. Furthermore CPu DA depletion was without effect on the biomarker of body weight whereas NAcc DA depletion (with moderate CPu DA depletion) led to reduced body weight. Nonetheless, a future study of effects of targeted, moderate $\mathrm{CPu}$ DA depletion on behaviour in the learned helplessness test, and treadmill test (see below) will be needed to fully clarify whether the effects of NAcc 6-OHDA obtained in these tests are completely attributable to NAcc DA depletion.

In rat, the mPFC has been demonstrated to be critical to the learning of un/controllability and is probably a region in which cognitive expectancy of stimulus control is processed: thus, GABA-mediated (picrotoxin) disinhibition of mPFC resulted in increased escape behaviour in subjects exposed to IS (Amat et al., 2008). In the present study, there were no effects of mPFC DA depletion on behaviour of mice in the LH test, suggesting that DA does not modulate mPFC-mediated cognitive expectancy aspects of the LH effect. These data are in accordance with the lack of effect of MPFC DA depletion on escape behaviour in rats exposed to IS (Ravard et al., 1990).

The footshock treadmill test allows for the assessment of active avoidance-escape from an aversive stimulus under effortful conditions. NAcc 6-OHDA resulted in a marked decrease in running time. The majority of DA-depleted mice ran for only 1-2 minutes of the test session until receiving the maximum footshock amount. These data suggest that NAcc DA depletion decreased the absolute level of effort mice are able/motivated to exert in order to maintain safety. The findings complement the evidence from the learned helplessness test that NAcc DA depletion decreased motivation to escape footshock following IS. Whilst it is important to note that the $\mathrm{LH}$ and treadmill tests were conducted with the same mice, the majority of Vehicle mice showed typical treadmill behaviour, i.e. they completed the 20-min test, indicating the absence of a major confounding effect of the LH test. Previous studies have used the footshock treadmill test to assess various factors, including prior physical exercise (Massett and Berk, 2005) and inflammation (Carmichael et al., 2006). It has been proposed as a readout test for fatigability, a core symptom of depression (DSM-5, 2013; ICD$10,1994)$. As noted above, the current findings suggest that NAcc DA depletion acts more to reduce absolute effort rather than cumulative effort, to avoid-escape aversion. Given the complexity of the construct fatigue, both states could be components of fatigue in depression. Thus, fatigue is proposed to comprise muscular, motivational, motor, emotional and cognitive components (Demyttenaere et al., 2005; Kluger et al., 2013). It has been proposed that deficient DA modulation of striatal and cortical regions is important in the pathophysiology of fatigue (Demyttenaere et al., 2005; Salamone et al., 2007). 
The third test in which effects of NAcc 6-OHDA on responsiveness to aversive stimuli were studied was Pavlovian fear conditioning. In contrast to the operant tests, there was no 6-OHDA effect on each of CS-US acquisition, context expression and CS expression, as measured using freezing behaviour. In rat, evidence as to whether exposure to aversive CSUS elicits increased extracellular DA in the NAcc is equivocal, with different findings being accommodated by proposing NAcc sub-region specificity (Levita et al., 2002; Wilkinson et al., 1998). Excitotoxic lesioning of the rat NAcc core was without effect on CS-US acquisition or expression or on context-US acquisition, but did reduce context expression of conditioned fear (Levita et al., 2002). Therefore, the previous rat and current mouse findings indicate that the NAcc is not a major contributor to the mesolimbic DA regulation of Pavlovian fear conditioning; the amygdala is a more likely region of DA action (Pezze and Feldon, 2004; Wenzel et al., 2015), and amygdala DA was not impacted by NAcc 6-OHDA injection. Thus, of the three tests in which mice were exposed to footshock, in two tests where active operant behaviour resulted in a reinforcing outcome NAcc DA depletion led to a deficit in behaviour, and in the test where behaviour was without consequence NAcc DA depletion was without effect.

\section{Conclusion and Outlook}

The present study provides important novel evidence that reduced DA activity in the NAcc of mice leads to reduced operant responding to: a stimulus that predicts reward under effortful conditions; a stimulus that now predicts reward but was recently associated with non-reward; escape an aversive stimulus recently experienced as uncontrollable; escape an aversive stimulus under effortful conditions. The findings obtained with the current operant test battery extend rat evidence for an important NAcc DA function in the PRS test to mouse, provide the first evidence for any species for an important NAcc DA function in the LNR test and treadmill test, and add to the overall understanding of the importance of NAcc DA as a modulator of motivation under physical or cognitive effort relative to both rewarding and aversive stimuli (Bromberg-Martin et al., 2010; Salamone and Correa, 2012; Wenzel et al., 2015). This study also adds to the evidence that motivational and motor functions of DA, classically attributed to the VTA-mesolimbic and SNC-nigrostriatal pathways, respectively, are intimately inter-related and can both be affected by NAcc DA deficiency (Haber, 2014; Sesack and Grace, 2010). Our rationale for establishing the present mouse test battery was to enable the integrated study of motivational processing of rewarding and aversive stimuli in this species. It can then be applied to investigate whether specific manipulations induce deficits in one or more of these processes that are of relevance to motivational domains in psychopathology. The evidence that NAcc DA deficiency impairs reward motivation under effortful or ambiguous conditions indicates its relevance to the RDoC of Positive valence 
systems, the core symptom of loss of interest in depression and the core negative symptoms in schizophrenia. The evidence that the same manipulation impairs aversion-conrol/safety motivation under ambiguous, uncontrollable or effortful conditions indicates its relevance to the RDoC of Negative valence systems, and the state of helplessness and the core symptom of fatigue in depression. That the battery enables detection of effects of a single manipulation on motivational processing of both reward and aversion indicates that it will facilitate the study and understanding of how reward and aversion processing are inter-related. We readily acknowledge that 6-OHDA DA depletion, even in a specific brain region, is a severe manipulation with little aetiological validity. Nonetheless, mouse environmental manipulations that do have aetiological validity, such as the chronic social defeat stressor, do indeed impact on DA signalling (Azzinnari et al., 2014; Chaudhury et al., 2013; Tanaka et al., 2012; Tye et al., 2013), and also lead to impaired aversion-safety motivation in the two-way escape and treadmill tests (Azzinnari et al., 2014), and impaired reward motivation in the PRS and LNR tests (Bergamini et al., unpublsihed data). The evidence that stress also alters effort-based decision making, biasing rats towards low effort/reward and away from high effort/reward (Shafiei et al., 2012), indicates that there are further important tests to be adapted for mice in translational models. Future studies can combine aetiologically valid genetic and environmental manipulations with a reward-aversion test battery, to identify the pathophysiological processes underlying motivational deficits, discover novel treatment targets, and screen the preclinical therapeutic efficacy of compounds developed for these targets.

\section{ACKNOWLEDGEMENTS}

We are extremely grateful to Björn Henz for animal care, and Christoph Porazik, Patrizia Voehringer and Peter Bauer for technical support. This research was funded by the Swiss National Science Foundation grant 31003A-141137 (to CRP and ES) and the FWF; SFB F44 (to NS).

\section{REFERENCES}

Aberman JE, Salamone JD (1999) Nucleus accumbens dopamine depletions make rats more sensitive to high ratio requirements but do not impair primary food reinforcement. Neuroscience 92, 545-552.

Allen CP, Leri F (2014) Perseveration in the presence of punishment: the effects of chronic cocaine exposure and lesions to the prefrontal cortex. Behav. Brain Res. 261, 185-192.

Amat JP, E, Watkins LR, Maier SF (2008) Activation of the ventral medial prefrontal cortex during an uncontrollable stressor reproduces both the immediate and long-term protective effects of behavioral control. Neuroscience 154, 1178-1186. 
Arrondo G, Segarra N, Metastasio A, Ziaudden H, Spencer J, Reinders NR, Dudas RB, Robbins TW, Fletcher PC, Murray GK (2015) Reduction in ventral striatal activity when anticipating a reward in depression and schizophrenia: a replicated cross-diagnostic finding. Frontiers in Psychology 6:128010.3389/fpsyg.2015.01280.

Azzinnari D, Sigrist H, Staehli S, Palme R, Hildebrandt T, Leparc G, Hengerer B, Seifritz E, Pryce CR (2014) Mouse social stress induces increased fear conditioning, helplessness and fatigue to physical challenge together with markers of altered immune and dopamine function. Neuropharmacology 85, 328-341.

Belujon P, Grace AA (2015) Regulation of dopamine system responsivity and its adaptive and pathological response to stress. Proc. R. Soc. Lond. B. Biol. Sci. 282.

Bergamini G, Cathomas F, Auer S, Sigrist H, Seifritz E, Patterson M, Gabriel C, Pryce CR Mouse psychosocial stress induces amotivation and cognitive deficits in operant reward tests: a model for reward pathology and effects of agomelatine.

Berridge KC, Robinson TE (1998) What is the role of dopamine in reward: hedonic impact, reward learning, or incentive salience? Brain Research Reviews 28, 309-369.

Bezzina G, Boon FS, Hampson CL, Cheung TH, Body S, Bradshaw CM, Szabadi E, Anderson IM, Deakin JF (2008) Effect of quinolinic acid-induced lesions of the subthalamic nucleus on performance on a progressive-ratio schedule of reinforcement: a quantitative analysis. Behav. Brain Res. 195, 223-230.

Bromberg-Martin ES, Matsumoto M, Hikosaka O (2010) Dopamine in motivational control: rewarding, aversive, and alerting. Neuron 68, 815-834.

Brown VJ, Bowman EM (2002) Rodent models of prefrontal cortical function. TINS 25, 340343.

Cabib S, Puglisi-Allegra S (2012) The mesoaccumbens dopamine in coping with stress. Neurosci. Biobehav. Rev. 36, 79-89.

Carmichael MD, Davis JM, Murphy EA, Brown AS, Carson JA, Mayer EP, Ghaffar A (2006) Role of brain IL-1B on fatigue after exercise-induced muscle damage. Am J Physiol Integr Comp Physiol 291, R1344-R1348.

Cathomas F, Stegen M, Sigrist H, Schmid L, Seifritz E, Gassmann M, Bettler B, Pryce CR (2015) Altered emotionality and neuronal excitability in mice lacking KCTD12, an auxillary subunit of GABAB receptors associated with mood disorders. Translational Psychiatry 5:e510. doi: 10.1038/tp.2015.8.

Chaudhury D, Walsh JJ, Friedman AK, Juarez B, Ku SM, Koo JW, Ferguson D, Tsai H-C, Pomeranz L, Christoffel DJ, Nectow AR, Ekstrand M, Domingos A, Mazei-Robison MS, Mouzon E, Lobo MK, Neve RL, Friedman JM, Russo SJ, Deisseroth K, Nestler EJ, Han M-H (2013) Rapid regulation of depression-related behaviours by control of midbrain dopamine neurons. Nature 493, 532-538. 
Clarke HF, Dalley JW, Crofts HS, Robbins TW, Roberts AC (2004) Cognitive inflexibility after prefrontal serotonin depletion. Science 304, 878-880.

Cools R, Nakamura K, Daw ND (2011) Serotonin and dopamine: unifying affective, activational, and decision functions. Neuropsychopharmacol 36, 98-113.

Cousins MS, Salamone JD (1994) Nucleus accumbens dopamine depletions in rats affect relative response allocation in a novel cost/benefit procedure. Pharmacol. Biochem. Behav. 49, 85-91.

Cuthbert BN, Insel TR (2013) Toward the future of psychiatric diagnosis: the seven pillars of RDoC. BMC Medicine 11, 126.

Darvas M, Fadok JP, Palmiter RD (2011) Requirement of dopamine signalling in the amygdala and striatum for learning and maintenance of a conditioned avoidance response. Learn. Mem. 18, 136-143.

Demyttenaere K, De Fruyt J, Stahl SM (2005) The many faces of fatigue in major depressive disorder. Int J Neuropsychopharmacol 8, 93-105.

Di Matteo V, De Blasi A, Di Giulio C, Esposito E (2001) Role of 5-HT(2C) receptors in the control of central dopamine function. Trends Pharmacol. Sci. 22, 229-232.

Dichter GS, Smoski MJ, Kampov-Polevoy AB, Gallop R, Garbutt JC (2010) Unipolar depression does not moderate responses to the sweet taste test. Depress. Anxiety 27, 859-863.

DSM-5 (2013) Diagnostic and Statistical Manual of Mental Disorders. 5th edn. Revision American Psychiatric Association, Washington, DC. American Psychiatric Association, Washington, DC.

Dunlop BW, Nemeroff CB (2007) The role of dopamine in the pathophysiology of depression. Arch. Gen. Psychiatry 64, 327-337.

Eshel N, Roiser JP (2010) Reward and punishment processing in depression. Biol Psychiatry 68, 118-124.

Floresco SB, Magyar O, Ghods-Sharifi S, Vexelman C, Tse MT (2006) Multiple dopamine receptor subtypes in the medial prefrontal cortex of the rat regulate set-shifting. Neuropsychopharmacology 31, 297-309.

Franklin KBJ, Paxinos G (2008) The Mouse Brain: in stereotaxic coordinates. Elsevier, Amsterdam.

Fuertig R, Azzinnari D, Bergamini G, Cathomas F, Sigrist H, Seifritz E, Vavassori S, Luippold A, Hengerer B, Ceci A, Pryce CR (2015) Mouse chronic social stress increases blood and brain kynurenine pathway activity and fear behaviour: both effects are reversed by inhibition of indoleamine 2 3-dioxygenase. Brain. Behav. Immun. XX, XX-XX.

Haber SN (2014) The place of dopamine in the cortico-basal ganglia circuit. Neuroscience 282, 248-257. 
Hagele C, Schlagenhauf F, Rapp M, Sterzer P, Beck A, Bermpohl F, Stoy M, Strohle A, Wittchen HU, Dolan RJ, Heinz A (2015) Dimensional psychiatry: reward dysfunction and depressive mood across psychiatric disorders. Psychopharmacology (Berl). 232, 331-341.

Haluk DM, Floresco SB (2009) Ventral striatal dopamine modulation of different forms of behavioral flexibility. Neuropsychopharmacology 34, 2041-2052.

Hamill S, Trevitt JT, Nowend KL, Carlson BB, Salamone JD (1999) Nucleus accumbens dopamine depletions and time-constrained progressive ratio performance: effects of different ratio requirements. Pharmacol. Biochem. Behav. 64, 21-27.

ICD-10 (1994) International Statistical Classification of Diseases and Related Health Problems. 10th Revision.

Ineichen C, Sigrist H, Spinelli S, Lesch K-P, Sautter E, Seifritz E, Pryce CR (2012) Establishing a probabilistic reversal learning test in mice: evidence for the processes mediating reward-stay and punishment-shift behaviour and for their modulation by serotonin. Neuropharmacol 63, 1012-1021.

Kluger BM, Krupp LB, Enoka RM (2013) Fatigue and fatigability in neurologic illnesses: proposal for a unified taxonomy. Neurology 80, 409-416.

Kravitz AV, Freeze BS, Parker PR, Kay K, Thwin MT, Deisseroth K, Kreitzer AC (2010) Regulation of parkinsonian motor behaviours by optogenetic control of basal ganglia circuitry. Nature 466, 622-626.

Lammel S, Hetzel A, Hackel O, Jones I, Liss B, Roeper J (2008) Unique properties of mesoprefrontal neurons within a dual mesocorticolimbic dopamine system. Neuron 57, 760-773.

Levita L, Dalley JW, Robbins TW (2002) Nucleus accumbens dopamine and learned fear revisited: a review and some new findings. Behav. Brain Res. 137, 115-127.

Lu A, Steiner MA, Whittle N, Vogl AM, Walser SM, Ableitner M, Refojo D, Ekker M, Rubenstein JL, Stalla GK, Singewald N, Holsboer F, Wotjak CT, Wurst W, Deussing JM (2008) Conditional mouse mutants highlight mechanisms of corticotropin-releasing hormone effects on stress-coping behavior. Mol Psychiatry 13, 1028-1042.

Maier SF, Seligman MEP (1976) Learned helplessness: theory and evidence. J Exp Psychol: General 105, 3-46.

Martinez-Hernandez J, Lanuza E, Martinez-Garcia F (2012) Lesions of the dopaminergic innervation of the nucleus accumbens medial shell delay the generation of preference for sucrose, but not of sexual pheromones. Behav. Brain Res. 226, 538-547.

Massett MP, Berk BC (2005) Strain-dependent differences in responses to exercise training in inbred and hybrid mice. Am J Physiol Regul Comp Physiol 288, R1006-R1013. 
McCullough LD, Sokolowski JD, Salamone JD (1993) A neurochemical and behavioral investigation of the involvement of nucleus accumbens dopamine in instrumental avoidance. Neuroscience 52, 919-925.

McGregor A, Baker G, Roberts DC (1996) Effect of 6-hydroxydopamine lesions of the medial prefrontal cortex on intravenous cocaine self-administration under a progressive ratio schedule of reinforcement. Pharmacol. Biochem. Behav. 53, 5-9.

Nilsson SRO, Ripley TL, Somerville EM, Clifton PG (2012) Reduced activity at the 5HT2C receptor enhances reversal learning by decreasing the influence of the previously nonrewarded associations. Psychopharmacol 224, 241-254.

Nunes EJ, Randall PA, Podurgiel S, Correa M, Salamone JD (2013) Nucleus accumbens neurotransmission and effort-related choice behavior in food motivation: Effects of drugs acting on dopamine, adenosine, and muscarinic acetylcholine receptors. Neurosci. Biobehav. Rev. 37, 2015-2025.

O'Neill M, Brown VJ (2007) The effect of striatal dopamine depletion and the adenosine A2A antagonist KW-6002 on reversal learning in rats. Neurobiol. Learn. Mem. 88, 75-81.

Oeckl P, Lattke M, Wirth T, Baumann B, Ferger B (2012) Astrocyte-specific IKK2 activation in mice is sufficient to induce neuroinflammation but does not increase susceptibility to MPTP. Neurobiol. Dis. 48, 481-487.

Palmiter RD (2008) Dopamine signaling in the dorsal striatum is essential for motivated behaviors: lessons from dopamine-deficient mice. Ann. N. Y. Acad. Sci. 1129, 35-46.

Pezze MA, Feldon J (2004) Mesolimbic dopaminergic pathways in fear conditioning. Prog. Neurobiol. 74, 301-320.

Pryce CR, Azzinnari D, Sigrist H, Gschwind T, Lesch K-P, Seifritz E (2012) Establishing a learned helplessness effect paradigm in C57BL/6 mice: behavioural evidence for emotional, motivational and cognitive effects of aversive uncontrollability per se. Neuropharmacol 62, 358-372.

Pryce CR, Azzinnari D, Spinelli S, Seifritz E, Tegethoff M, Meinlschmidt G (2011) Helplessness: a systematic translational review of theory and evidence for its relevance to understanding and treating depression. Pharmacol Ther 132, 242-267.

Ravard S, Carnoy P, Herve D, Tassin JP, Thiebot MH, Soubrie P (1990) Involvement of prefrontal dopamine neurones in behavioural blockade induced by controllable vs uncontrollable negative events in rats. Behav Brain Res 37, 9-18.

Reading PJ, Dunnett SB (1991) The effects of excitotoxic lesions of the nucleus accumbens on a matching to position task. Behav. Brain Res. 46, 17-29.

Salamone JD, Correa M (2012) The mysterious motivational functions of mesolimbic dopamine. Neuron 76, 470-485. 
Salamone JD, Correa M, Farrar A, Mingote SM (2007) Effort-related functions of nucleus accumbens dopamine and associated forebrain circuits. Psychopharmacology (Berl). 191, 461-482.

Sesack SR, Grace AA (2010) Cortico-basal ganglia reward network: microcircuitry. Neuropsychopharmacology 35, 27-47.

Shafiei N, Gray M, Viau V, Floresco SB (2012) Acute stress induces selective alterations in cost/benefit decision-making. Neuropsychopharmacology 37, 2194-2209.

Smith KS, Berridge KC, Aldridge JW (2011) Disentangling pleasure from incentive salience and learning signals in brain reward circuitry. PNAS 108, E255-E264.

Son JH, Kuhn J, Keefe KA (2013) Perseverative behavior in rats with methamphetamineinduced neurotoxicity. Neuropharmacology 67, 95-103.

Stott SR, Barker RA (2014) Time course of dopamine neuron loss and glial response in the 6-OHDA striatal mouse model of Parkinson's disease. Eur. J. Neurosci. 39, 1042-1056.

Tait DS, Brown VJ (2007) Difficulty overcoming learned non-reward during reversal learning in rats with ibotenic acid lesions of orbital prefronal cortex. Ann NY Acad Sci 1121, 407420 .

Tanaka K, Furuyashiki T, Kitaoka S, Senzai Y, Imoto Y, Segi-Nishida E, Deguchi Y, Breyer RM, Breyer MD, Narumiya S (2012) Prostaglandin E2-mediated attenuation of mesocortical dopaminergic pathway is critical for susceptibility to repeated social defeat stress in mice. J Neurosci 32, 4319-4329.

Thiele SL, Warre R, Nash JE (2012) Development of a unilaterally-lesioned 6-OHDA mouse model of Parkinson's disease. J Vis Exp.

Treadway MT, Bossaller N, Shelton RC, Zald DH (2012) Effort-based decision-making in major depressive disorder: a translational model of motivational anhedonia. J. Abnorm. Psychol. 121, 553-558.

Treadway MT, Zald DH (2011) Reconsidering anhedonia in depression: Lessons from translational neuroscience. Neurosci. Biobehav. Rev. 35, 537-555.

Tye KM, Deisseroth K (2012) Optogenetic investigation of neural circuits underlying brain disease in animal models. Nature Rev Neurosci 13, 251-266.

Tye KM, Mirzabekov JJ, Warden MR, Ferenczi EA, Tsai H-C, Finkelstein J, Kim S-Y, Adhikari A, Thompson KR, Andalman AS, Gunaydin LA, Witten IB, Deisseroth K (2013) Dopamine neurons modulate neural encoding and expression of depression-related behaviour. Nature 493, 537-543.

van der Plasse G, Feenstra MG (2008) Serial reversal learning and acute tryptophan depletion. Behav. Brain Res. 186, 23-31. 
van Schouwenburg M, Aarts E, Cools R (2010) Dopaminergic modulation of cognitive control: distinct roles for the prefrontal cortex and the basal ganglia. Curr. Pharm. Des. 16, 2026-2032.

Wang J, Huang J, Yang X-h, Lui SSY, Cheung EFC, Chan RCK (2015) Anhedonia in schizophrenia: Deficits in both motivation and hedonic capacity. Schizophr. Res. 168, 465474

Wenzel JM, Rauscher NA, Cheer JF, Oleson EB (2015) A role for phasic dopamine release within the nucleus accumbens in encoding aversion: a review of the neurochemical literature. ACS Chemical Neuroscience 6, 16-26.

Whitton AE, Treadway MT, Pizzagalli DA (2015) Reward processing dysfunction in major depression, bipolar disorder and schizophrenia. Current Opinion in Psychiatry 30, 531534.

Wilkinson LS, Humby T, Killcross AS, Torres EM, Everitt BJ, Robbins TW (1998) Dissociations in dopamine release in medial prefrontal cortex and ventral striatum during the acquisition and extinction of classicial aversive conditioning in the rat. Eur. J. Neurosci. 10, 1019-1026.

Winter C, von Rumohr A, Mundt A, Petrus D, Klein J, Lee T, Morgenstern R, Kupsch A, Juckel G (2007) Lesions of dopaminergic neurons in the substantia nigra pars compacta and in the ventral tegmental area enhance depressive-like behavior in rats. Behav. Brain Res. 184, 133-141.

Wise RA (2004) Dopamine, learning and motivation. Nature Reviews Neuroscience 5, 1-12. Young AM, Joseph MH, Gray JA (1993) Latent inhibition of conditioned dopamine release in rat nucleus accumbens. Neuroscience 54, 5-9.

\section{FIGURE CAPTIONS}

Figure 1. Immunohistochemical staining for tyrosine hydroxylase to delineate the extent of the depletion of dopaminergic fibres following (A) Vehicle or (B) 6-OHDA injection targeting the nucleus accumbens. Brains were perfused at day 12 post-injection. The coronal images of the mouse striata show depletion of tyrosine hydroxylase positive fibres in the NAcc core and shell following injection of 6-OHDA (B) specifically. Scale bar $=1 \mathrm{~mm}$.

Figure 2. Effects of NAcc 6-OHDA lesion (Vehicle, $1.5 \mathrm{ug}$ and $2 \mu \mathrm{g}$ 6-OHDA) on behavioural measures in the progressive ratio schedule test. A) Mean +/- SD cumulative scores for number of pellets earned at $10,20,30$ and $40 \mathrm{~min} .{ }^{*} p<0.05,{ }^{* *} p<0.01$ for 2 ug 6 -OHDA vs 
Vehicle. B) Mean +/- SD cumulative scores for ratio attained at 10, 20, 30 and 40 min. ** $p<0.01$ for 2ug 6-OHDA vs Vehicle. C) Scatterplot and mean for post-reinforcement pause (PRP, seconds (s)). ${ }^{* *} p<0.01,{ }^{* * * *} p<0.0001$. D) Absolute peak response rate (PRR). Values in parentheses indicate the ratio at which the PRR was achieved. ${ }^{*} p<0.05$. Significant 6OHDA effects were obtained with ANOVA followed by Bonferonni post hoc testing.

Figure 3. Effects of NAcc 6-OHDA lesion (Vehicle and $2 \mu \mathrm{g} \mathrm{6-OHDA)} \mathrm{on} \mathrm{behavioural}$ measures in the spatial discrimination (SD) and learned non-reward (LNR) stages of the LNR test. A) Pre-lesion testing: mean+SD scores for total errors in stages SD1-3 and stages LNR1-3 prior to NAcc 6-OHDA lesion; mice were allocated to Vehicle and 6-OHDA groups by counter-balancing on LNR3 total-error scores. B) Post-NAcc 6-OHDA lesion testing: mean+SD scores in SD4 and LNR4 tests for, omissions to initiate a trial (OIT), incorrect choice responses (IR) and total errors (TE). ${ }^{*} p<0.05,{ }^{* *} p<0.01,{ }^{* * *} p<0.001$. Significant 6OHDA effects were obtained with ANOVA or unpaired $t$-tests.

Figure 4. Effects of NAcc 6-OHDA lesion (Vehicle $(\mathrm{N}=13)$ and $2 \mu \mathrm{g}$ 6-OHDA $(\mathrm{N}=14)$ ) on behavioural measures in the learned helplessness paradigm. Data are given as scatterplot + mean. A) Activity test. Escape test: B) Inter-shock interval locomotor activity, C) Mean escape latency (maximum footshock duration $=5 \mathrm{~s}$ ), D) Total escape failures, E) Total escape failures in blocks of 10 trials, and F) Footshock reactivity. In E), significant post-hoc differences between trial blocks obtained with ANOVA are indicated by different letters. In F), outlier values (according to Grubbs' test) indicated with a were not included in the unpaired $t$ test. ${ }^{*} p<0.05,{ }^{* * *} p<0.001$.

Figure 5. Effects of NAcc 6-OHDA lesion (Vehicle $(\mathrm{N}=13)$ and $2 \mu \mathrm{g}$ 6-OHDA $(\mathrm{N}=14)$ ) on behavioural measures at the training and test sessions of the treadmill test. Mice were the same as those studied in the learned helplessness paradigm. Scatterplot and mean scores for A) Total footshock duration (s) in the training session, B) Running time achieved in the test session, and C) Total footshock duration in the test session. ${ }^{* * *} p<0.001{ }^{* * * *} p<0.0001$, obtained with unpaired $t$-tests.

Figure 6. Lack of effects of NAcc 6-OHDA lesion (Vehicle and $2 \mu \mathrm{g} 6-\mathrm{OHDA}$ ) on \% time spent freezing (mean +/- SD) in the Pavlovian tone (CS) - footshock (US) fear conditioning paradigm. A) Freezing acquisition during CS-US conditioning, B) Freezing expression to context, and C) Freezing expression to tone CS. 
Table 4. Effects of mPFC 6-OHDA infusion on performance in the learned helplessness test

\begin{tabular}{|c|c|c|c|c|c|c|c|}
\hline & & \multicolumn{2}{|c|}{ Activity } & \multicolumn{2}{|c|}{ IE footshock } & \multicolumn{2}{|c|}{ Escape test } \\
\hline & & Veh & 6-OHDA & Veh & 6-OHDA & Veh & 6-OHDA \\
\hline \multirow{2}{*}{$\begin{array}{l}\text { Locomotor } \\
\text { activity }\end{array}$} & $x$ & 8583 & 8856 & 4636 & 4249 & 5653 & 5736 \\
\hline & SD & 1442 & 1924 & 945 & 1111 & 1170 & 1436 \\
\hline \multirow{2}{*}{$\%$ time freezing } & $x$ & 2.0 & 2.7 & 6.2 & 9.2 & 5.9 & 6.8 \\
\hline & SD & 1.6 & 2.1 & 3.5 & 5.7 & 3.5 & 3.7 \\
\hline \multirow{2}{*}{ Escape failures } & $x$ & & & & & 9.5 & 13.1 \\
\hline & SD & & & & & 7.8 & 9.9 \\
\hline \multirow{2}{*}{ Escape latency } & $x$ & & & & & 3.2 & 3.5 \\
\hline & SD & & & & & 1.0 & 1.1 \\
\hline \multirow{2}{*}{$\begin{array}{l}\text { Footshock } \\
\text { reactivity }\end{array}$} & $x$ & & & & & 163 & 149 \\
\hline & SD & & & & & 49 & 57 \\
\hline
\end{tabular}


Table 3. Effects of mPFC 6-OHDA infusion on performance in simple (SD) and learned nonreward (LNR) discrimination

\begin{tabular}{clcccc} 
& & \multicolumn{2}{c}{ SD } & \multicolumn{2}{c}{ LNR } \\
\cline { 3 - 6 } & & Veh & $6-O H D A$ & Veh & 6 -OHDA \\
\hline \multirow{2}{*}{ OIT } & $\mathrm{X}$ & 2.0 & 1.2 & 15.1 & 10.1 \\
& SD & 3.1 & 1.7 & 24.7 & 10.3 \\
& & & & & \\
IR & $\mathrm{X}$ & 10.3 & 16.1 & 56.5 & 74.9 \\
& SD & 15.5 & 16.6 & 34.9 & 49.9 \\
& & & & & \\
TE & $\mathrm{X}$ & 16.7 & 17.8 & 94.9 & 103.7 \\
& SD & 25.5 & 18.1 & 78.1 & 81.8 \\
\hline
\end{tabular}

Scores are mean \pm SD.

OIT, omissions to initiate a trial; IR, incorrect choice responses; TE, total errors 
Table 2. Effects of NAcc, mPFC or CPu 6-OHDA infusion on tissue dopamine in brain regions of interest

Dopamine (ng/mg tissue)

\begin{tabular}{|c|c|c|c|c|c|c|c|c|c|c|c|}
\hline & & & & Icc & $\mathrm{CF}$ & $\mathrm{Pu}$ & & $\mathrm{FC}$ & Amy & gdala & \\
\hline $\begin{array}{l}\text { Target } \\
\text { region }\end{array}$ & Behavioural test & & Veh & $\begin{array}{c}6- \\
\text { OHDA }\end{array}$ & Veh & $\begin{array}{c}6- \\
\text { OHDA }\end{array}$ & Veh & $\begin{array}{c}6- \\
\text { OHDA }\end{array}$ & Veh & $\begin{array}{c}\text { 6- } \\
\text { OHDA }\end{array}$ & $\begin{array}{l}\text { Post 6- } \\
\text { OHDA } \\
\text { (days) }\end{array}$ \\
\hline NAcc & $\begin{array}{l}\text { Progressive ratio } \\
\text { schedule }\end{array}$ & $x$ & 3.31 & $0.86^{c}$ & 15.70 & $22.47^{\mathrm{C}}$ & 0.29 & $\begin{array}{l}<0.05 \\
(\mathrm{LLOQ}\end{array}$ & & & 14 \\
\hline & $(\mathrm{N}=8 \mathrm{Veh}, 8$ 6-OHDA $)$ & SD & 1.19 & 0.64 & 1.57 & 4.82 & 0.41 & ) & & & \\
\hline NAcc & Learned non-reward & $x$ & 4.92 & $1.04^{C}$ & 19.09 & 20.88 & 0.25 & $<0.05$ & & & \\
\hline & $(\mathrm{N}=10,9)$ & SD & 1.64 & 0.52 & 4.73 & 4.44 & 0.24 & $\begin{array}{c}\text { (LLOQ } \\
\text { ) }\end{array}$ & & & 21 \\
\hline NAcc & Learned helplessness \& & $x$ & 6.89 & $0.90^{c}$ & 19.37 & $15.35^{b}$ & 0.12 & $0.05^{b}$ & 1.89 & 2.10 & \\
\hline & Treadmill $(\mathrm{N}=13,14)$ & $S$ & 2.04 & 0.79 & 3.13 & 2.78 & 0.08 & 0.04 & 1.44 & 1.33 & 19 \\
\hline & & $\mathrm{D}$ & & & & & & & & & \\
\hline NAcc & Activity $(\mathrm{N}=10,10)$ & $\mathrm{X}$ & 8.04 & $1.63^{c}$ & 15.35 & 15.37 & 0.15 & $0.02^{c}$ & & & \\
\hline & & $S$ & 2.35 & 1.66 & 1.88 & 5.36 & 0.10 & 0.00 & & & 11 \\
\hline & & $\mathrm{D}$ & & & & & & & & & \\
\hline $\mathrm{CPu}$ & Activity $(N=5,4)$ & $\mathrm{X}$ & 6.35 & 5.58 & 14.45 & $0.17^{c}$ & 0.12 & $0.02^{c}$ & 1.06 & 1.09 & \\
\hline & & $S$ & 3.40 & 2.50 & 1.20 & 0.11 & 0.01 & 0.01 & 0.53 & 0.74 & 13 \\
\hline & & $\mathrm{D}$ & & & & & & & & & \\
\hline NAcc & Fear conditioned freezing & $\mathrm{X}$ & 6.45 & $1.43^{c}$ & 14.61 & 13.66 & 0.14 & $0.02^{C}$ & 1.06 & 0.97 & \\
\hline & $(\mathrm{N}=11,11)$ & $S$ & 1.29 & 0.36 & 2.02 & 2.61 & 0.07 & 0.04 & 0.39 & 0.35 & 13 \\
\hline & & $\mathrm{D}$ & & & & & & & & & \\
\hline mPFC & Learned non-reward & $x$ & 6.08 & 7.28 & 13.20 & 14.55 & 0.24 & $0.08^{a}$ & & & \\
\hline & $(\mathrm{N}=15,15)$ & $S$ & 1.63 & 1.77 & 3.77 & 4.31 & 0.22 & 0.11 & & & 19 \\
\hline & & $\mathrm{D}$ & & & & & & & & & \\
\hline mPFC & Learned helplessness & $x$ & 7.16 & 8.59 & 13.71 & 14.98 & 0.07 & $0.01^{b}$ & 2.31 & 2.20 & \\
\hline & & S & & & & & & 0.01 & & & 24 \\
\hline & $(\mathrm{N}=12,12)$ & $\mathrm{D}$ & 1.48 & 2.66 & 2.79 & 5.21 & 0.06 & 0.01 & 1.54 & 1.19 & \\
\hline
\end{tabular}

6-OHDA dose was $2 \mu \mathrm{g}$ per hemisphere for NAcc, $1.5 \mu \mathrm{g}$ per hemisphere for mPFC and $3.5 \mu \mathrm{g}$ per hemisphere for $\mathrm{CPu}$

Concentrations are mean \pm SD.

Post 6-OHDA: number of days between 6-OHDA/vehicle injection and brain collection.

For NAcc-PRS experiment and NAcc-LNR experiments, where a less sensitive flowcell was used for HPLC-ED, mPFC DA levels were below the lower limit of quantification (LLOQ) in 6-OHDA mice.

a $\mathrm{p}<0.05, b \mathrm{p}<0.01, c \mathrm{p}<0.001$. 

Table 1. Study behavioural tests, associated outcome and effort, and integration into the RDoC framework ${ }^{1}$

\begin{tabular}{|c|c|c|c|c|}
\hline Test & $\begin{array}{l}\text { Outcome } \\
\text { (Stimulus) }\end{array}$ & Effort & RDoC domain & Dimension \\
\hline $\begin{array}{l}\text { Progressive ratio } \\
\text { schedule }\end{array}$ & Sweet taste & Physical & Positive valence & $\begin{array}{l}\text { Gustatory approach } \\
\text { motivation }\end{array}$ \\
\hline $\begin{array}{l}\text { 1. Learned non- } \\
\text { reward }\end{array}$ & $\begin{array}{l}\text {-ve operant } \\
\text { stimulus } \\
\text { Food/sweet taste }\end{array}$ & Cognitive & $\begin{array}{l}\text { Negative } \\
\text { valence } \\
\text { Cognitive }\end{array}$ & Learned irrelevance \\
\hline $\begin{array}{l}\text { 2. -ve to +ve } \\
\text { Reversal learning }\end{array}$ & & & $\begin{array}{l}\text { systems } \\
\text { Positive } \\
\text { systems }\end{array}$ & $\begin{array}{l}\text { Reward learning } \\
\text { Approach motivation }\end{array}$ \\
\hline $\begin{array}{l}\text { 1. Inescapable } \\
\text { aversion } \\
\text { 2. Two-way active } \\
\text { escape } \\
\text { (Learned } \\
\text { helplessness) }\end{array}$ & $\begin{array}{l}\text { Footshock pain } \\
\text { Escape footshock }\end{array}$ & $\begin{array}{l}\text { Physical, } \\
\text { Cognitive }\end{array}$ & $\begin{array}{l}\text { Negative } \\
\text { valence } \\
\text { Cognitive } \\
\text { systems } \\
\text { Positive valence }\end{array}$ & $\begin{array}{l}\text { Acute threat (Fear) } \\
\text { Loss of control } \\
\text { Safety motivation }\end{array}$ \\
\hline $\begin{array}{l}\text { Treadmill, one-way } \\
\text { active avoidance- } \\
\text { escape }\end{array}$ & $\begin{array}{l}\text { Avoid-escape } \\
\text { footshock }\end{array}$ & Physical & $\begin{array}{l}\text { Negative } \\
\text { valence Positive } \\
\text { valence }\end{array}$ & $\begin{array}{l}\text { Acute threat (Fear) } \\
\text { Safety motivation }\end{array}$ \\
\hline CS Fear conditioning & Fear & & $\begin{array}{l}\text { Negative } \\
\text { valence }\end{array}$ & Acute threat (Fear) \\
\hline
\end{tabular}

1 RDoC and dimension nomenclature based on Cuthbert \& Insel (2013) and NIMH Guidelines. -ve, Negative; +ve, Positive 


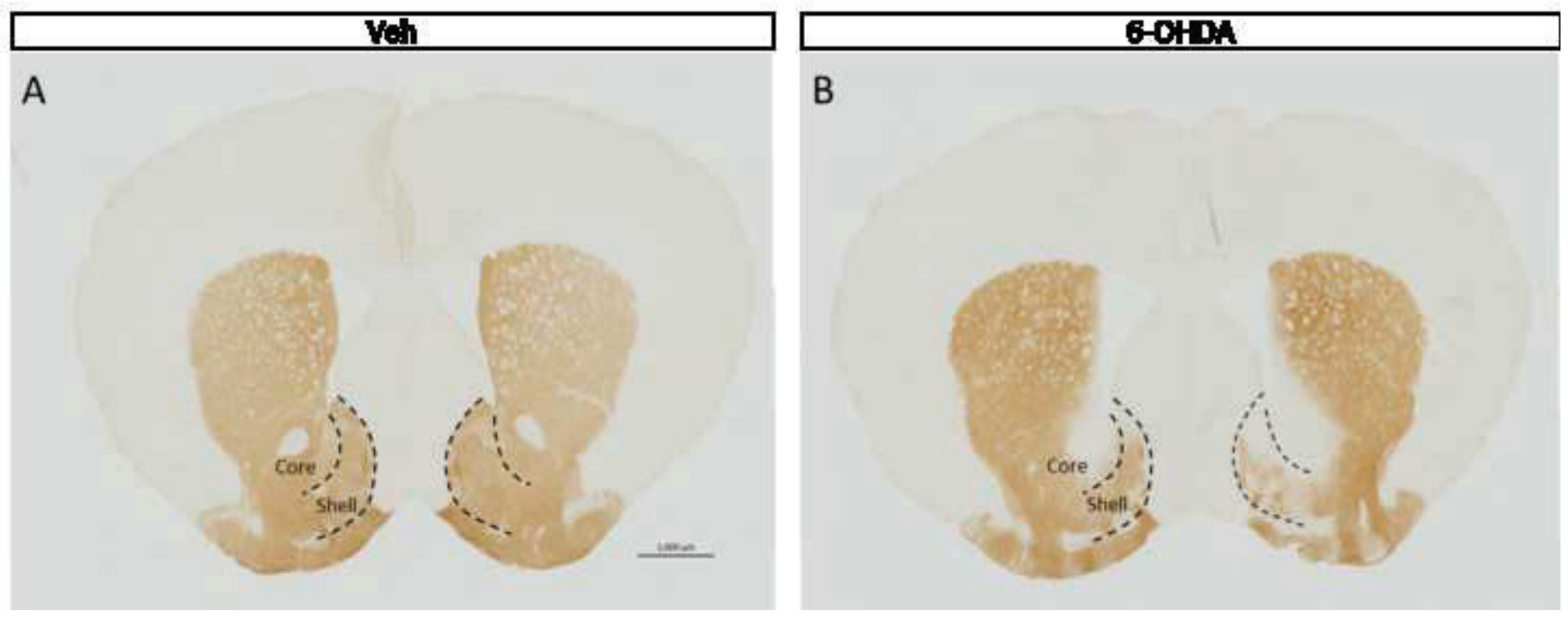


Figure 2
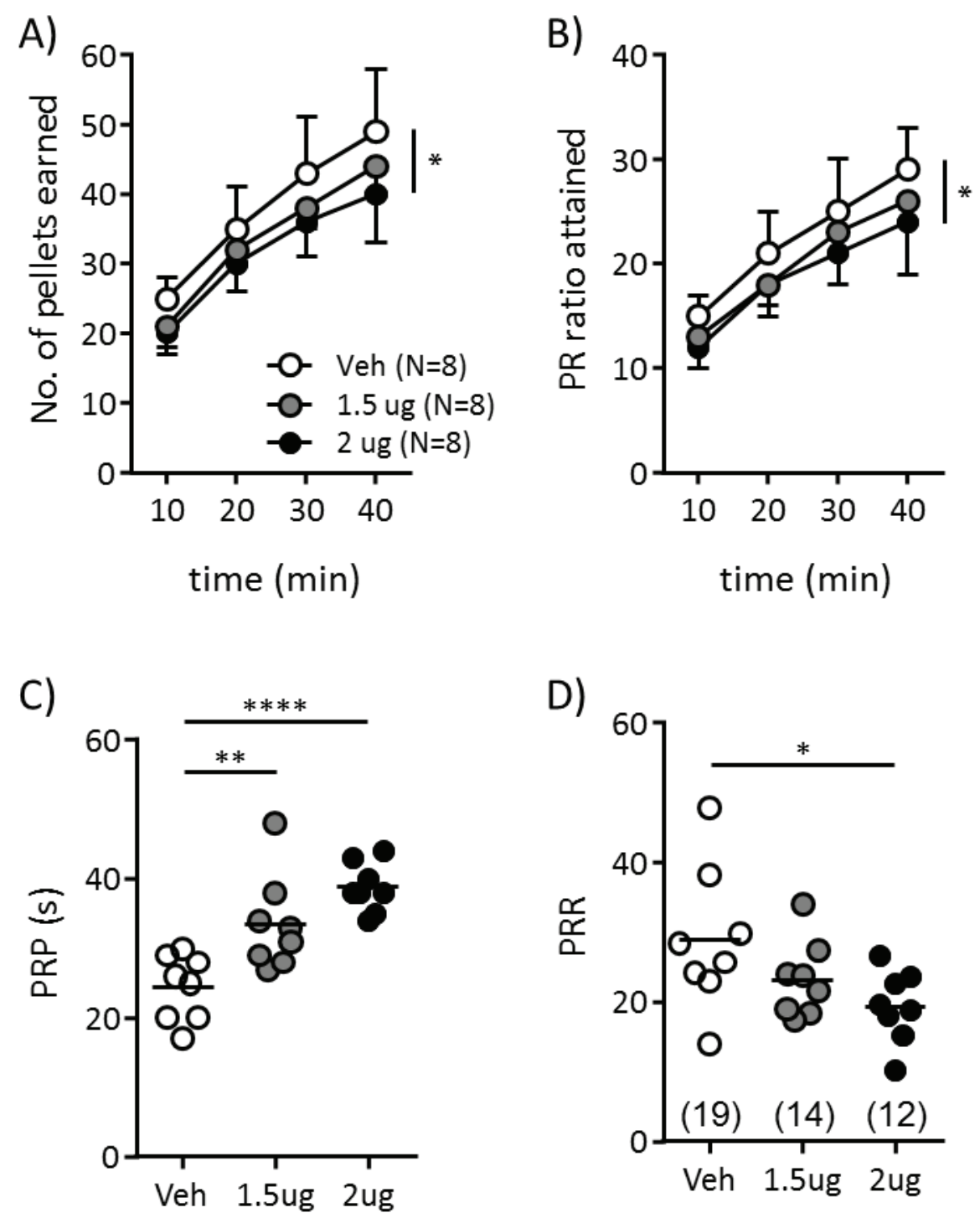


\section{Figure 3}
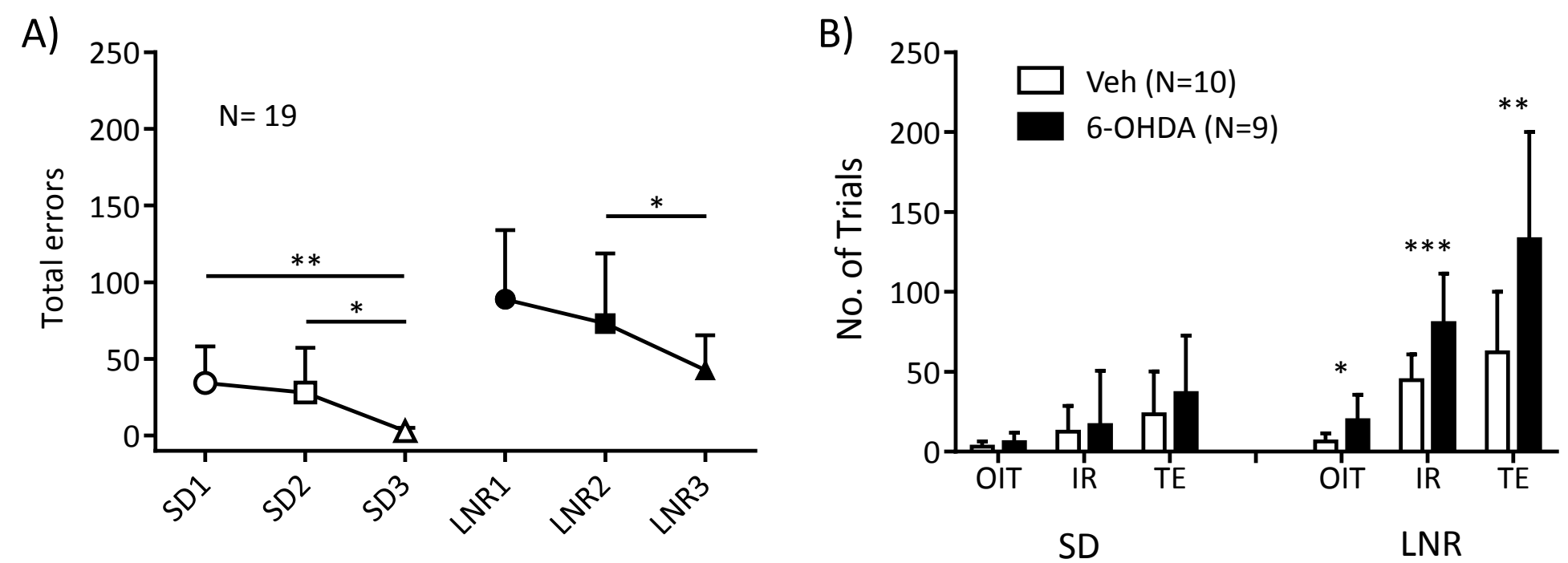
Figure 4

A)

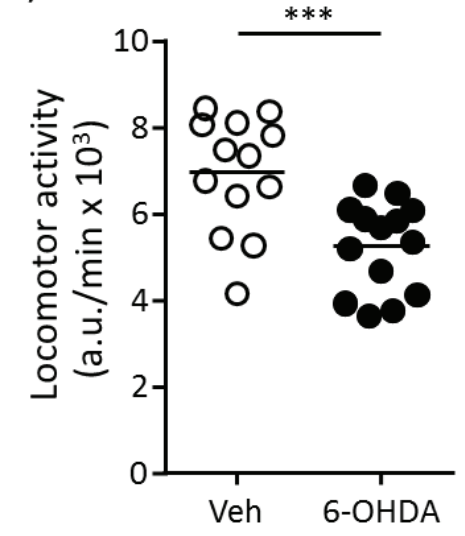

D)

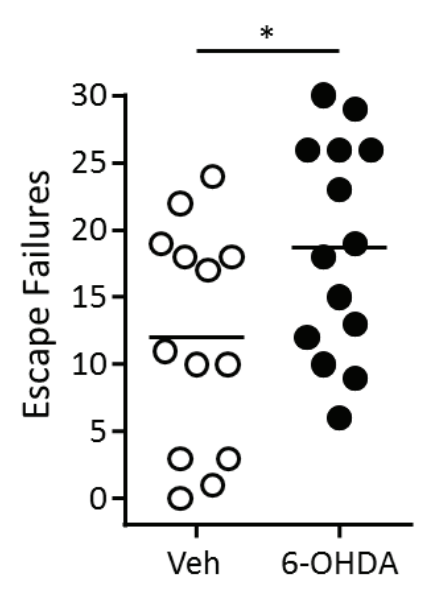

B)

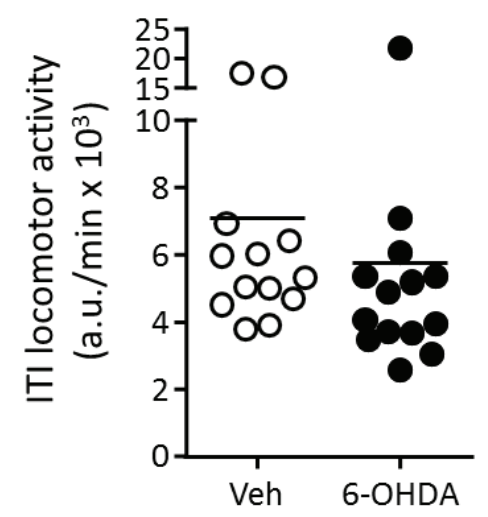

E)

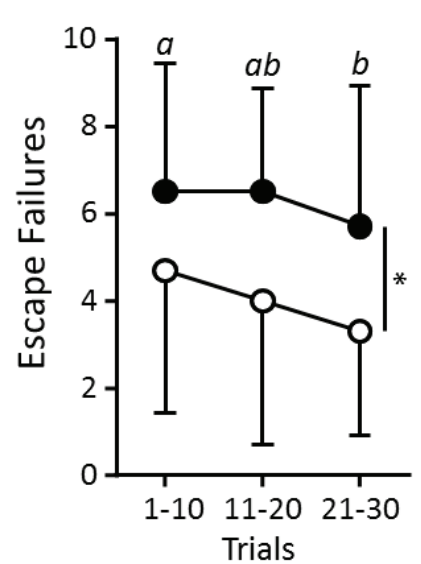

C)

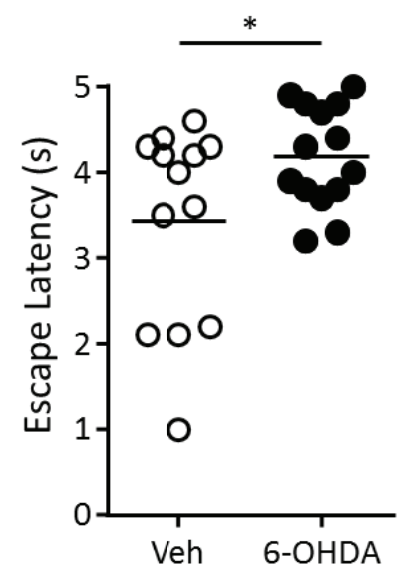

F)

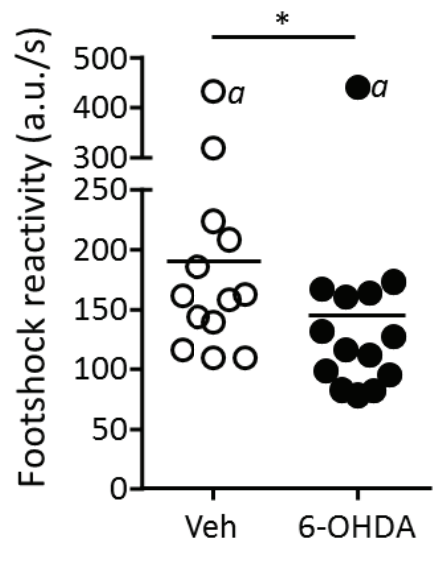


Figure 5
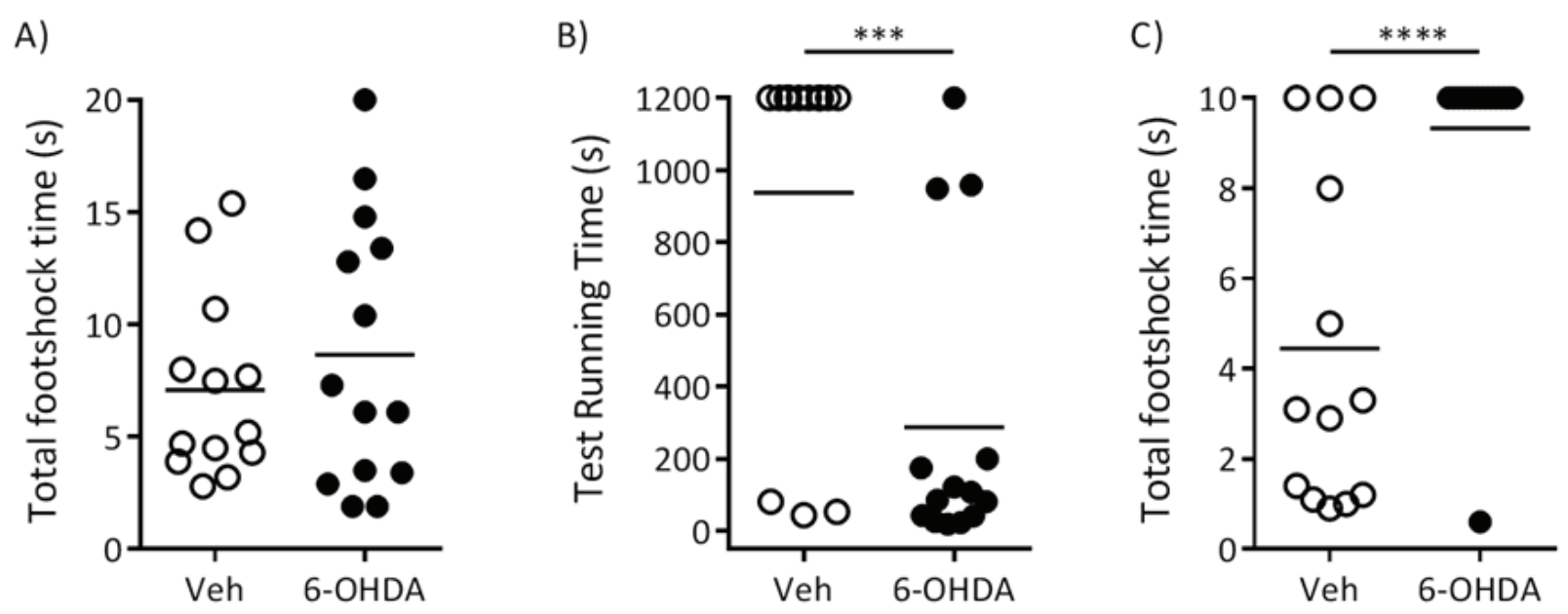
Figure 6
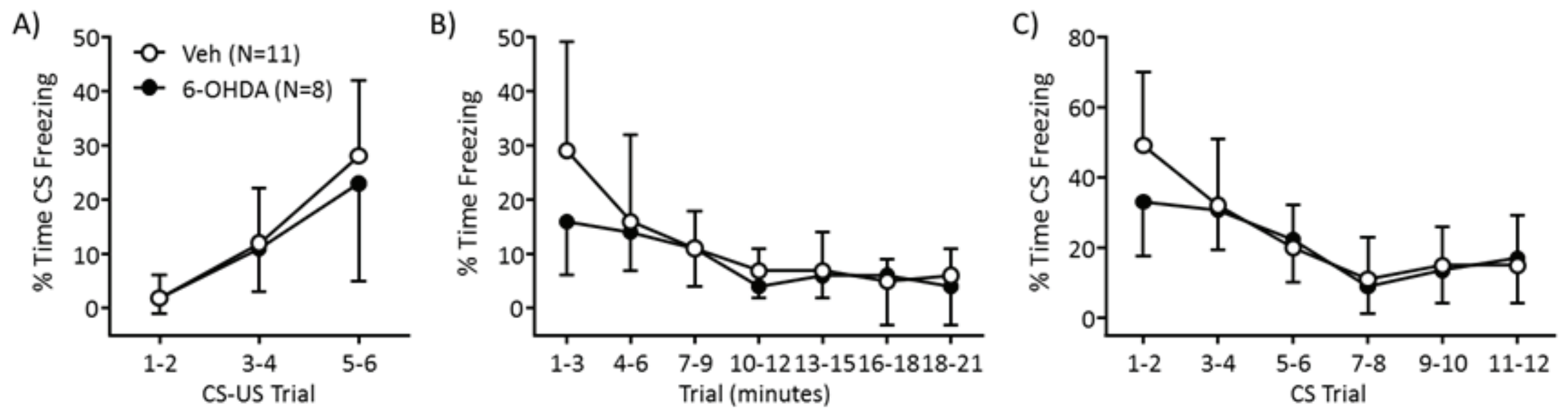